\title{
Microphysical and optical properties of dust and tropical biomass burning aerosol layers in the Cape Verde region-an overview of the airborne in situ and lidar measurements during SAMUM-2
}

\author{
By BERNADETT WEINZIERL ${ }^{1 *}$, DANIEL SAUER ${ }^{2,1}$, MICHAEL ESSELBORN $^{3,1}$, \\ ANDREAS PETZOLD ${ }^{1}$, ANDREAS VEIRA ${ }^{1}$, MAXIMILIAN ROSE ${ }^{1}$, SUSANNE MUND ${ }^{1}$, \\ MARTIN WIRTH ${ }^{1}$, ALBERT ANSMANN ${ }^{4}$, MATTHIAS TESCHE ${ }^{4}$, SILKE GROSS ${ }^{2}$, and \\ VOLKER FREUDENTHALER ${ }^{2}, \quad{ }^{1}$ Deutsches Zentrum für Luft- und Raumfahrt (DLR), Institut für Physik der \\ Atmosphäre, 82234 Oberpfaffenhofen, Germany; ${ }^{2}$ Ludwig-Maximilians-Universität München, Meteorologisches \\ Institut, Theresienstraße 37, 80333 München, Germany; ${ }^{3}$ European Southern Observatory, Technology Division, \\ Karl-Schwarzschild-Str 2, 85748 Garching bei München, Germany; ${ }^{4}$ Physics Department, Leibniz Institut for \\ Tropospheric Research (IfT), Permoserstraße 1504318 Leipzig, Germany
}

(Manuscript received 23 December 2010; in final form 6 June 2011)

\begin{abstract}
In the framework of the Saharan Mineral Dust Experiment (SAMUM) airborne High Spectral Resolution Lidar and in situ measurements of the particle size, aerosol mixing state and absorption coefficient were conducted. Here, the properties of mineral dust and tropical biomass burning layers in the Cape Verde region in January/February 2008 are investigated and compared with the properties of fresh dust observed in May/June 2006 close the Sahara. In the Cape Verde area, we found a complex stratification with dust layers covering the altitude range below $2 \mathrm{~km}$ and biomass burning layers aloft. The aerosol type of the individual layers was classified based on depolarization and lidar ratios and, in addition, on in situ measured Ångström exponents of absorption $\stackrel{\circ}{a p}_{\text {ap }}$. The dust layers had a depth of $1.3 \pm$ $0.4 \mathrm{~km}$ and showed a median $\stackrel{\circ}{a p}_{\text {ap }}$ of 3.95. The median effective diameter $D_{\text {eff }}$ was $2.5 \mu \mathrm{m}$ and the dust layers over Cape Verde yielded clear signals of aging: large particles were depleted due to gravitational settling and the accumulation mode diameter was shifted towards larger sizes as a result of coagulation. The tropical biomass layers had a depth of $2.0 \pm 1.1 \mathrm{~km}$ and were characterized by a median $\stackrel{\circ}{a}_{\text {ap }}$ of 1.34 . They always contained a certain amount of large dust particles and showed a median $D_{\text {eff }}$ of $1.1 \mu \mathrm{m}$ and a fine mode $D_{\text {eff, fine }}$ of 0.33 . The dust and biomass burning layers had a median aerosol optical depth (AOD) of 0.23 and 0.09 , respectively. The median contributions to the AOD of the total atmospheric column below $10 \mathrm{~km}$ were 75 and $37 \%$, respectively.
\end{abstract}

\section{Introduction}

Mineral dust particles impact the global climate in many ways. The presence of dust alters atmospheric heating rates, influences the hydrological cycle (e.g. Miller et al., 2004), and affects the formation of ice clouds (e.g. Ansmann et al., 2005). Furthermore, dust particles have the potential to alter the outgoing terrestrial radiation flux due to their large sizes (e.g. Haywood et al., 2005). Although mineral dust plays an important role for

\footnotetext{
* Corresponding author.

e-mail: bernadett.weinzierl@dlr.de

DOI: $10.1111 /$ j.1600-0889.2011.00566.x
}

the global climate system, the spatial and temporal distribution of dust properties is poorly understood over many regions of the world (e.g. Moorthy et al., 2007). Major unknowns are the dust size distribution that spans a range from $0.01 \mu \mathrm{m}$ to about $100 \mu \mathrm{m}$, dust refractive index and absorption coefficient and the vertical distribution of dust microphysical and optical properties (Sokolik et al., 2001). The size distribution of dust particles is of critical importance in the estimation of dust radiative forcing (Myhre and Stordal, 2001). However, the size distribution of mineral dust is difficult to measure and requires the combination of several in situ instruments which cover the size range from some nm to several tens of micrometres (Petzold et al., 2009; Weinzierl et al., 2009; Müller et al., 2010). 
In the past, several field experiments investigating the properties of mineral dust have been performed (a detailed overview of dust field experiments performed in the past few years is given in Ansmann et al., 2011). The Saharan Mineral Dust Experiment (SAMUM) was the most comprehensive dust closure experiment performed within the past few years. It had a strong emphasis on the vertical profiling of dust optical properties and involved several ground-based Raman/polarization lidars together with an airborne High Spectral Resolution Lidar (HSRL), which was operated on the DLR (Deutsches Zentrum für Luft- und Raumfahrt) Falcon, a twin-engine jet aircraft. Besides the nadir-looking HSRL, the DLR Falcon research aircraft was equipped with an extensive set of aerosol instruments for size (diameter range between $10 \mathrm{~nm}$ and several tens of $\mu \mathrm{m}$ ), volatility $(0.1-2.5 \mu \mathrm{m})$, absorption measurements (particle diameter $D_{\mathrm{p}}<2.5 \mu \mathrm{m}$ ), impactor sampling for chemical analyses (Kandler et al., 2011; Lieke et al., 2011) and radiation measurements (Bauer et al., 2011). Furthermore, meteorological parameters (temperature, horizontal wind speed and humidity) and aircraft parameters (position, aircraft speed, etc.) were recorded.

Within the SAMUM project, two field experiments were performed. SAMUM-1, conducted in May/June 2006 in Morocco, focused on the properties of pure dust close to the source region of mineral dust. The second field experiment, SAMUM-2, took place in the Cape Verde area in January/February 2008 and focused on the transformation of the dust properties during transport and mixing with biomass burning aerosol. The mixing of dust layers with biomass burning aerosol, which occurs quite frequently at the southern edge of the African dust belt in the winter season (Prospero et al., 2002), is expected to modify the optical properties of dust quite significantly.

In this study, we present an overview of the DLR Falcon research flights performed during SAMUM-2. Important objectives addressed here are the vertical structure of the atmosphere in the Cape Verde region, the absorption properties and the size distribution of the dust and biomass burning aerosol layers observed during SAMUM-2. The microphysical properties of dust measured during SAMUM-2 are compared with those measured during SAMUM-1 and the impact of aging on the microphysical properties of mineral dust is discussed. The mixing of urban pollution from Dakar with mineral dust is investigated in detail in Petzold et al. (2011). The analyses are performed on the basis of in situ as well as HSRL aerosol data collected during numerous flights of the research aircraft Falcon, which acted as the major research platform for SAMUM-2.

\section{Methods}

The instrumentation operated on the DLR Falcon research aircraft during SAMUM-2 was similar to the instrumentation used during SAMUM-1 (Esselborn et al., 2009; Petzold et al., 2009; Weinzierl et al., 2009). New instruments added for the SAMUM-
2 payload, were the SMART albedometer (Bauer et al., 2011) and the Giant Particle Collector (GPaC; Lieke et al., 2011). A summary of the instrumentation on board of the DLR Falcon can be found in Table 1.

\subsection{Airborne aerosol in situ measurements during SAMUM-2}

The in situ aerosol instrumentation covered a large particle size spectrum including particles in the nucleation mode $\left(D_{\mathrm{p}}>4 \mathrm{~nm}\right)$ up to large coarse mode particles in the far super-micron size range. The sub-100 nm particle fraction was sized by a set of condensation particle counters (CPCs), which were operated at different cut-off diameters (cf. Table 1). A Differential Mobility Analyser (DMA) was operated in a stepping mode at diameters $0.015,0.03,0.05,0.08,0.12$ and $0.16 \mu \mathrm{m}$. The super-100 nm particle fraction was sized by a combination of Optical Particle Counters (OPC): PMS Passive Cavity Aerosol Spectrometer Probe (PCASP-100X), Grimm SKY-OPC 1.129 (Grimm OPC), and Forward Scattering Spectrometer Probe (FSSP-300). The measurement principle of these instruments is the sizing of particles based on the detection of the amount of light scattered by single particles. The instruments convert the scattering signal into an electrical signal, which corresponds to size information and is resolved into an array of channels that is fixed in the case of the three aerosol spectrometers used in this study. The instruments differ mainly in optical geometry and electronic signal processing and, as a result, cover different particle size ranges. According to the manufacturers, the PCASP-100X covers nominally the size range $0.12-3.5 \mu \mathrm{m}$ (15 channels), the Grimm OPC the size range $0.25-32 \mu \mathrm{m}$ (32 channels) and the FSSP-300 the size range $0.3-30 \mu \mathrm{m}$ ( 31 channels). However, the actual size range of the instruments depends on the refractive index used for the derivation of particle size distributions from OPC data and shifts to larger sizes in the case of absorbing particles (for more detail see Weinzierl et al., 2009; Schumann et al., 2011).

The PCASP-100X, the FSSP-300 and the GPaC were mounted under the wings of the aircraft. All other instruments were operated in the cabin, sampling air from a nearly isokinetic aerosol inlet. For large particles, the sampling efficiency of this inlet falls off rigorously. The cut-off diameter, at which $50 \%$ of the particles pass the isokinetic inlet, depends on outside pressure and air speed. For typical Falcon speed, the cut-off is near $2.5 \mu \mathrm{m}$ at ground level and decreases to about $1.5 \mu \mathrm{m}$ at $10 \mathrm{~km}$ altitude (Fiebig, 2001; Wendisch et al., 2004).

To determine the size distribution of non-volatile aerosol compounds, which provides insight into the aerosol mixing state, the Grimm OPC and two of the CPCs were connected to a thermal denuder heating the aerosol to $250^{\circ} \mathrm{C}$ (for more details on mixing state derivation from these measurements see Weinzierl et al., 2009). The DMA was by default connected to the heated sampling line. However, it was possible to switch between heated 
Table 1. Instrumentation on board the Falcon aircraft during SAMUM-2 in January/February 2008. The isokinetic aerosol inlet operated on board the Falcon has a cut-off diameter of about $2.5 \mu \mathrm{m}$, depending on outside pressure and temperature. The upper diameter given for instruments operated inside the cabin refers to the cut-off diameter of the aerosol inlet

\begin{tabular}{|c|c|}
\hline Instrumentation & Property \\
\hline \multicolumn{2}{|c|}{ Aerosol in situ instruments operated inside the cabin of the Falcon behind an isokinetic inlet $\left(\sim D_{\mathrm{p}}<2.5 \mu \mathrm{m}\right)$} \\
\hline $\begin{array}{l}\text { Multi-channel condensation particle counter } \\
\text { (CPC; } 3 \text { unheated, } 2 \text { heated channels) }\end{array}$ & $\begin{array}{l}\text { Integral number concentration of ultrafine particles }\left(0.004<D_{\mathrm{p}}<\right. \\
2.5 \mu \mathrm{m}) \text { and non-volatile particle fraction }\end{array}$ \\
\hline $\mathrm{TD}\left(250^{\circ} \mathrm{C}\right)+\mathrm{CPC} / \mathrm{DMA}$ & Size distribution non-volatile/total Aitken mode $\left(0.01<D_{\mathrm{p}}<0.2 \mu \mathrm{m}\right)$ \\
\hline $\mathrm{TD}\left(250^{\circ} \mathrm{C}\right)+\mathrm{Grimm}$ OPC & Non-volatile size distribution $\left(0.25<D_{\mathrm{p}}<2.5 \mu \mathrm{m}\right)$ \\
\hline $3 \lambda$-PSAP & Absorption coefficient at $\lambda=467,530$ and $660 \mathrm{~nm}$ \\
\hline $1 \lambda$-PSAP & Absorption coefficient at $\lambda=530 \mathrm{~nm}\left(D_{\mathrm{p}}<1 \mu \mathrm{m}\right)$ \\
\hline Filter sampling & Chemical composition and shape of fine mode particles \\
\hline \multicolumn{2}{|l|}{ Aerosol in situ instruments sampling at wing stations } \\
\hline PCASP-100X & $\begin{array}{l}\text { Dry state accumulation mode (nominal size range: } 0.12 \mu \mathrm{m}<D_{\mathrm{p}}< \\
\quad 3.5 \mu \mathrm{m} \text { ) }\end{array}$ \\
\hline FSSP-300 & $\begin{array}{l}\text { Ambient state accumulation }+ \text { coarse mode (nominal size range : } 0.1< \\
\left.D_{\mathrm{p}}<30 \mu \mathrm{m}\right)\end{array}$ \\
\hline Giant Particle Collector (GPaC) & Chemical composition and shape of coarse mode particles \\
\hline \multicolumn{2}{|l|}{ Remote-sensing instruments } \\
\hline \multirow[t]{6}{*}{ High Spectral Resolution Lidar (HSRL) } & Backscatter at $\lambda=532,925$ and $1064 \mathrm{~nm}$ \\
\hline & Extinction coefficient at $\lambda=532 \mathrm{~nm}$ \\
\hline & Lidar ratio at $\lambda=532 \mathrm{~nm}$ \\
\hline & $\mathrm{AOD}$ at $\lambda=532$ and $1064 \mathrm{~nm}$ \\
\hline & Depolarization at $\lambda=532$ and $\lambda=1064 \mathrm{~nm}$ \\
\hline & Water vapour at $\lambda=925 \mathrm{~nm}$ \\
\hline Albedometer (SMART) & Upward spectral irradiance $(300 \mathrm{~nm}<\lambda<2200 \mathrm{~nm})$ \\
\hline \multicolumn{2}{|l|}{ Meteorological data } \\
\hline Falcon standard instrumentation & $T, p, R H(\mathrm{BL}, \mathrm{FT}), 3 \mathrm{D}$-wind velocity \\
\hline
\end{tabular}

and unheated sampling line. The heating temperature of the thermal denuder allows the separation of high to medium volatile organics and components of sulphuric acid-like and ammonium sulphate-like behaviour from non-volatile or refractory components like mineral dust, black carbon, sea salt and crustal material (Clarke, 1991).

Besides particle sizing, the aerosol absorption coefficient was measured by a single-channel (1 $\lambda$ PSAP: $\lambda=530 \mathrm{~nm}$; Bond et al., 1999) and a multiple-channel Particle Soot Absorption Photometer ( $3 \lambda$ PSAP: $\lambda=467,530$ and $660 \mathrm{~nm}$; Virkkula et al., 2005; Virkkula, 2010). While the $3 \lambda$ PSAP was connected to the isokinetic aerosol inlet, the $1 \lambda$ PSAP was connected to a different inlet and allowed the measurement of the absorption coefficient in sub-1- $\mu \mathrm{m}$ size range (Petzold et al., 2011). The absorption data from the $3 \lambda$ PSAP were used to determine the complex refractive index by an inversion method which is described in more detail in Petzold et al. $(2009 ; 2011)$ and summarized in Section 2.4. To determine the chemical composition and morphology of the aerosol particles, six impactor sampling devices were mounted inside the aircraft and particles were collected for off-line single particle analysis. The results of the single particle analysis are summarized in Lieke et al. (2011).

\subsection{Airborne Lidar measurements during SAMUM-2}

The setup of the airborne High-Spectral-Resolution-Lidar (HSRL) system for remote sensing of aerosol layers was largely identical to the one employed during SAMUM-1. The instrument and its specifications are described in detail in Esselborn et al. (2008; 2009). Here we repeat only the most important aspects.

The HSRL is a nadir-viewing lidar system that employs narrow band optical filters to separate the backscatter signal from molecules and aerosol particles. Therefore it allows direct measurement of aerosol extinction and backscatter coefficients without the additional assumption of the lidar ratio (the ratio of the particle extinction coefficient to the particle backscatter coefficient). The system operates at a pulse rate of $100 \mathrm{~Hz}$ at two wavelengths, 532 and $1064 \mathrm{~nm}$. In addition to extinction and backscatter properties, it can also measure the linear particle depolarization ratio at those wavelengths. The linear particle depolarization ratio is obtained from the ratio of cross-polarized to parallel-polarized backscatter signal (the linear volume depolarization ratio) by correcting for the influence of molecular Rayleigh scattering (Freudenthaler et al., 2009). The vertical resolution of the measurements is $15 \mathrm{~m}$. The resolution of the extinction and lidar ratio profiles is degraded to $360-700 \mathrm{~m}$ because 
those quantities are derived through numerical differentiation of the measured aerosol optical depth (AOD) (Esselborn et al., 2009). According to the assessments in Esselborn et al. (2008), we use the following estimates for systematic uncertainties in the HSRL measurements: within dust layers the backscatter measurements have a 4-8\% systematic error, extinction measurements have a $5 \%$ systematic error, and the depolarization ratio measurements have up to $16 \%$ systematic error. Compared to the setup during SAMUM-1, a new laser which had a higher degree of spectral purity was used such that the error estimates in Esselborn et al. (2008) can be regarded as conservative.

The lidar data were used to explore the horizontal and vertical extent of aerosol layers and to extract vertical profiles of optical properties. For this purpose, the data were averaged over segments of the HSRL flight path in which the aerosol layer structure was sufficiently homogenous. To validate the results, the extinction and depolarization profile comparisons with groundbased lidar systems stationed at Praia airport during the campaign (Groß et al., 2011b; Tesche et al., 2011b) were performed for a number of direct overpasses on different days. The lidar measurements from different ground-based instruments are generally in reasonable agreement within the error bars. We compared the extinction coefficients and depolarization ratios measured by MULIS (operated by the Meteorological Institute of the University of Munich, see Groß et al., 2011b) and the HSRL. The deviations of the extinction coefficients are on average around $7.5 \%$. In our comparison, the depolarization ratios measured by the HSRL tend to be smaller than seen by MULIS; the average deviation is $12 \%$. The differences in the lidar data observed during SAMUM-2 are somewhat larger than during SAMUM-1 (Freudenthaler et al., 2009). This is likely caused by the geographic location leading to larger temporal variability, which makes it more difficult to ensure a comparison of identical atmospheric conditions especially given the long integration times of MULIS (about $2 \mathrm{~h}$ ) compared to the HSRL (a few seconds).

\subsection{SAMUM-2 research flights and sampling strategy}

During the SAMUM-2 field phase, the DLR Falcon operated from the International Airport of Praia, the capital of the Republic of Cape Verde $\left[14.9^{\circ} \mathrm{N}, 23.5^{\circ} \mathrm{W}\right.$, about $70 \mathrm{~m}$ above sea level (a.s.1.)] on the island of Santiago and took measurements between 19 January and 9 February 2008. Details on the flights are compiled in Table 2. The flight tracks of all flights performed during SAMUM-1 and SAMUM-2 are summarized in Fig. 1. Figure 2 shows images from the Meteosat Second Generation satellite (MSG) for all days with science flights. For every flight, the MSG image corresponding to the mean time between take-off and landing of the Falcon was selected. It can be seen that almost no clouds were present along the flight routes. Furthermore, on all satellite images layers of biomass burning and mineral dust aerosol are visible as brownish areas. The flights were designed such that the aerosol layers were sampled by both airborne remote sensing and in situ instruments. During the flights, the HSRL allowed the online monitoring and measurement of the atmospheric stratification, especially the structure of the aerosol layers. Thus, the HSRL acted as a path finder to direct the aircraft into the aerosol plumes to take in situ measurements. After take-off, the Falcon climbed to an altitude between 8 and $10 \mathrm{~km}$ and probed the structure of the atmosphere. During every flight, 1-2 vertical profiles providing in situ aerosol data were performed. These in situ profiles covered the altitude range between a few hundred metres and up to $10 \mathrm{~km}$ altitude. Based on the HSRL measurements, certain altitudes were selected online for constant-altitude measurements. During these constantaltitude sequences the Falcon stayed in the selected altitude for 5-10 min. Depending on the true air speed of the Falcon, $10 \mathrm{~min}$ of flight time correspond to a horizontal distance of 90-120 km. The measurements on constant altitude sequences ensure good statistics and a large number of data points in a particular aerosol plume and thus, result in the characteristic stepped flight profile. Figure 3 shows the locations of the individual constant altitude sequences.

\subsection{Data reduction, derivation of microphysical and optical aerosol properties and parametrization of in situ data}

The derivation of particle size distributions and absorption coefficients was reduced to constant altitude sequences inside of aerosol layers outside of clouds. During every Falcon flight, the constant altitude sequences were consecutively numbered with a Layer ID (e.g. L03). Figure 4 shows a time series of particle number concentration for the descent over Praia on 19 January 2008. The grey and yellow shaded areas depict the vertical extent of the biomass burning and dust layer as derived from the HSRL extinction measurements. All lower and upper boundaries of aerosol layers reported in this study were derived from the HSRL data. During this descent, in situ sequences at constant altitudes were performed at $4.1 \mathrm{~km}$ (L03), $2.5 \mathrm{~km}$ (L04) and $0.9 \mathrm{~km}$ (L05), respectively. For each in situ sequence, the data were averaged (symbols in Fig. 4) over homogeneous periods (usually the entire constant-altitude sequence) and size distributions were calculated from CPC, PCASP-100X and FSSP-300 data. As can be seen from Fig. 4, the natural variability within one averaging interval is largest for particles larger than $3 \mu \mathrm{m}$.

The particle number size distribution in the Aitken mode $\left(D_{\mathrm{p}}<0.16 \mu \mathrm{m}\right)$ was derived from the CPC data. We assumed that a single log-normal mode represents all particles in the Aitken mode. This assumption is justified because the contribution of particles in the nucleation mode $\left(D_{\mathrm{p}}<10 \mathrm{~nm}\right)$ was negligible in most of the 65 constant altitude sequences investigated in this study (see Table 3). The total number of Aitken mode particles was calculated as the total condensation nuclei concentration from CPC measurement $\left(D_{\mathrm{p}}>10 \mathrm{~nm}\right)$ minus the 
Table 2. List of Falcon flights during the SAMUM-2 field experiment in January/February 2008. OP, Oberpfaffenhofen (Germany); F, Faro (Portugal); TS, Tenerife South (Canary Islands); PRA, Praia (Cape Verde Islands); D, Dakar (Senegal); SA, South Atlantic; NW.C., Northwest of Cape Verde

\begin{tabular}{|c|c|c|c|c|c|}
\hline $\begin{array}{l}\text { Mission } \\
\text { ID }\end{array}$ & $\begin{array}{l}\text { Date } \\
(2008)\end{array}$ & $\begin{array}{l}\text { Take-off time } \\
\text { [UTC) }\end{array}$ & $\begin{array}{l}\text { Landing time } \\
\text { [UTC) }\end{array}$ & $\begin{array}{l}\text { Flight } \\
\text { route }\end{array}$ & Mission objective/ aerosol types \\
\hline 080119a & 19 January & $07: 23$ & $10: 25$ & $\mathrm{OP}-\mathrm{F}$ & Transfer flight \\
\hline $080119 b$ & & $11: 16$ & $13: 29$ & $\mathrm{~F}-\mathrm{TS}$ & Transfer flight \\
\hline $080119 \mathrm{c}$ & & $15: 09$ & $17: 46$ & TS - PRA & Elevated biomass burning layer above dust \\
\hline 080122a & 22 January & 13:09 & $16: 55$ & PRA - SA - PRA & Elevated biomass burning layer above dust \\
\hline 080123a & 23 January & $14: 55$ & $18: 38$ & PRA - SA - PRA & Elevated biomass burning layer above dust \\
\hline $080125 \mathrm{a}$ & 25 January & $14: 47$ & $17: 09$ & PRA - PRA & Column closure study: biomass burning aerosol above mineral dust \\
\hline $080128 \mathrm{a}$ & 28 January & 09:50 & $12: 52$ & PRA - TS & $\begin{array}{l}\text { Dust storm over the Western Sahara: cross wind traversing of dust } \\
\text { plumes of different origins }\end{array}$ \\
\hline $080128 b$ & & $14: 36$ & 18:03 & TS - PRA & \\
\hline $080129 \mathrm{a}$ & 29 January & $12: 52$ & $15: 44$ & PRA - D & $\begin{array}{l}\text { Dust storm over the Western Sahara: quasi-Langrangian sampling } \\
\text { of dust \& mixing of urban pollution and dust (high dust loading) }\end{array}$ \\
\hline $080129 b$ & & $17: 03$ & $20: 46$ & $\mathrm{D}-\mathrm{PRA}$ & \\
\hline 080130a & 30 January & $16: 50$ & 20:04 & PRA - NW.C. - PRA & $\begin{array}{l}\text { Dust storm over the Western Sahara: low-level sampling of dust } \\
\text { over the Atlantic Ocean }\end{array}$ \\
\hline $080204 \mathrm{a}$ & 4 February & $15: 39$ & $19: 30$ & PRA - SA - PRA & Mixing of dust and biomass burning aerosol (layered structure) \\
\hline $080205 \mathrm{a}$ & 5 February & $14: 45$ & $18: 34$ & PRA - D - PRA & $\begin{array}{l}\text { Dust and biomass burning plumes \& mixing of dust and urban } \\
\text { pollution (moderate dust loading) }\end{array}$ \\
\hline 080206a & 6 February & 14:07 & $17: 17$ & PRA - PRA & Column closure study : elevated biomass burning layer \\
\hline 080209a & 9 February & 08:59 & $11: 26$ & PRA - TS & Transfer flight \\
\hline 080209b & & $12: 49$ & $14: 40$ & $\mathrm{TS}-\mathrm{F}$ & Transfer flight \\
\hline $080209 \mathrm{c}$ & & $15: 25$ & $18: 54$ & $\mathrm{~F}-\mathrm{OP}$ & Transfer flight \\
\hline
\end{tabular}

Fig. 1. Map of Western Africa and South-Western Europe, with the location of the SAMUM-1 and SAMUM-2 ground sites Ouarzazate, Zagora and Praia indicated. The flight tracks of the SAMUM-1 and SAMUM-2 research flights are shown in black and blue, respectively. The brown and orange shaded areas schematically indicate the pathways of the mineral dust and tropical biomass burning layers investigated during SAMUM.

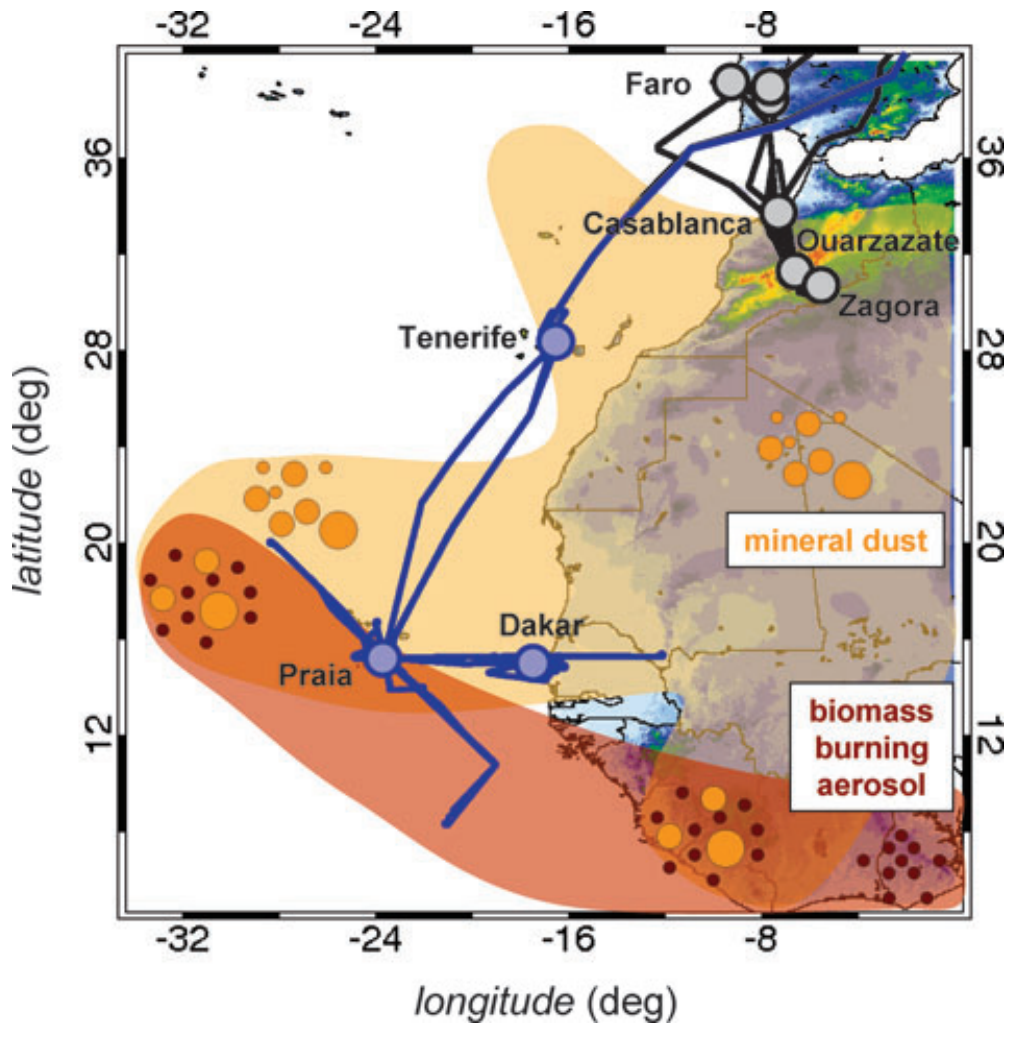



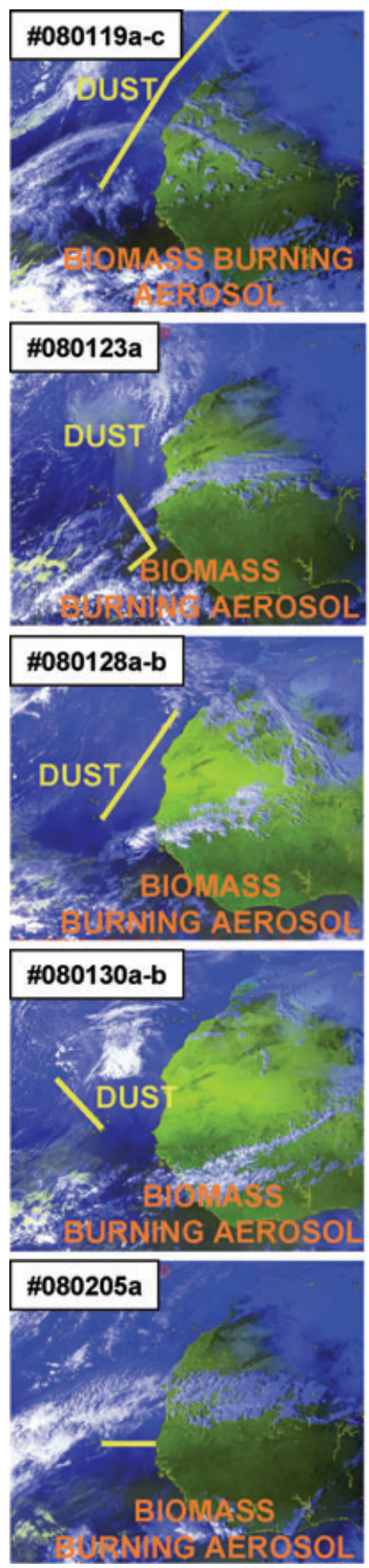
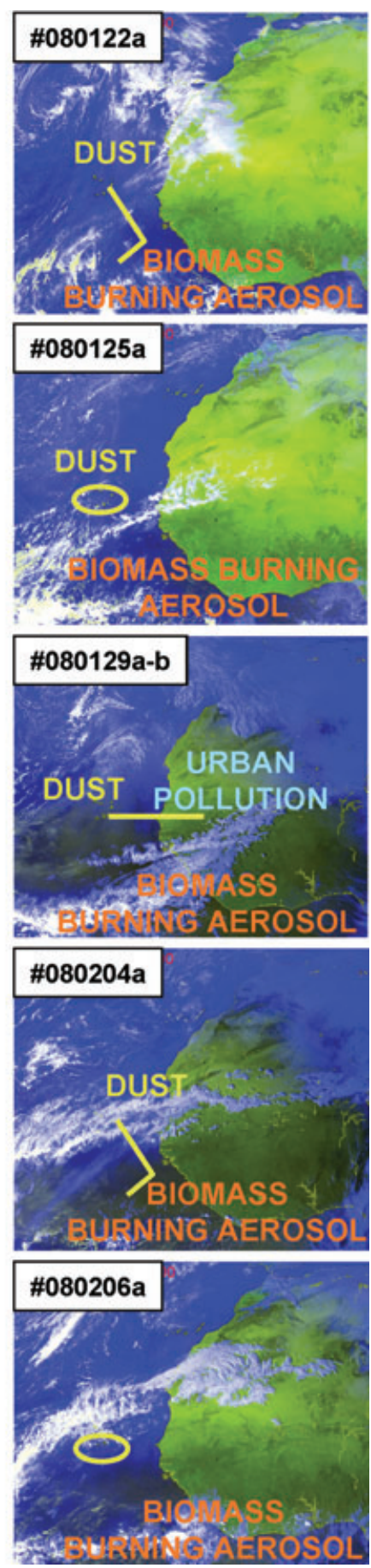

Fig. 2. MSG satellite images for all days with science flights. For every flight, the MSG image corresponding to the mean flight time was selected. The yellow lines/circles denote the Falcon flight path. The brownish areas are regions with high dust and biomass burning aerosol load (MSG images: courtesy of Hermann Mannstein, DLR). total amount of accumulation mode particles from the PCASP$100 \mathrm{X}$. The scale $\left(C M D_{\text {Aitken }}\right)$ and shape parameters $\left(G S D_{\text {Aitken }}\right)$ for the log-normal Aitken mode were adjusted such that the shape of the Aitken mode fit matched the shape of the size distribution measured with the PCASP-100X. The particle number size distribution in the accumulation and coarse mode $\left(D_{\mathrm{p}}>\right.$ $0.16 \mu \mathrm{m})$ was derived from the analysis of the PCASP-100X and FSSP-300 data. Figure 5 shows an example for a composite size distribution derived from various instruments. During the Falcon flights discussed in this study, we found the FSSP-300 to show false counts due to electronic noise in the two lowest channels. Therefore these channels were disregarded in the data analysis. This shifts the lower detection limit of the FSSP-300 to about $0.4 \mu \mathrm{m}$. A critical parameter for the determination of 
Fig. 3. Map of SAMUM-2 flight routes with the location of the 65 constant altitude sequences indicated by diamonds. The aerosol type measured at the individual sequences is colour-coded and the numbers refer to the layer-ID of the constant altitude sequences. 33 sequences were flown above Praia and south of the Praia over the sea. 11 sequences were flown north and north-west of the island of Santiago, 10 sequences refer to measurements in the South Atlantic, and 11 sequences belong to measurements in the Dakar region and above Senegal.

Fig. 4. Time series of particle number concentration (black, green and orange line) measured above Praia on 19 January 2008. The dashed black line indicates the flight altitude of the Falcon and the symbols depict the layer averages of the particle number concentration on the respective constant altitude sequence. For every Falcon flight, the constant altitude sequences were consecutively numbered with a Layer ID (e.g. L03). The grey shaded areas show the vertical extent of the biomass burning and the mineral dust layer as derived from the HSRL measurements (see also Tables 4 and 8).
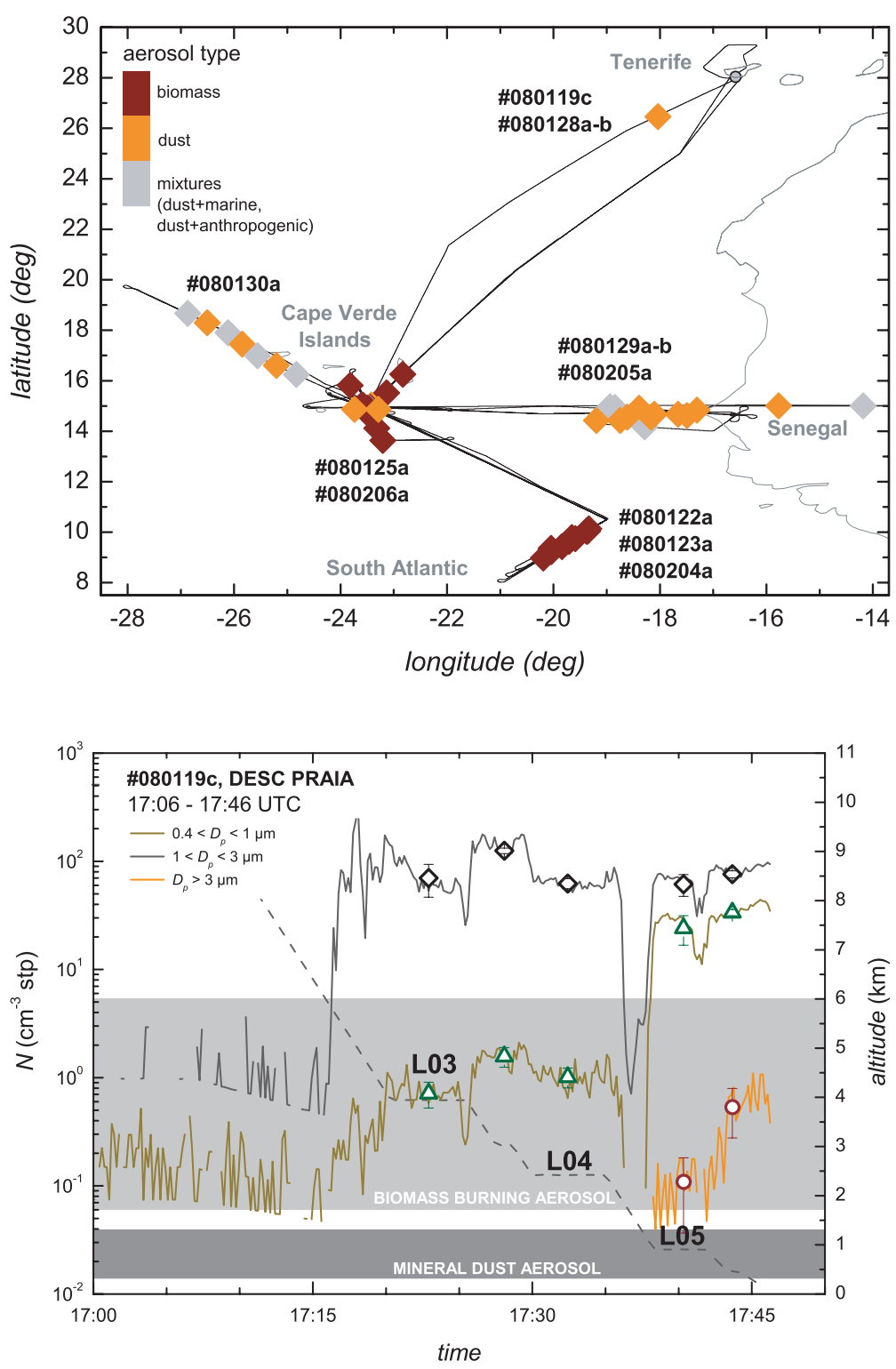

particle number concentrations from the PCASP-100X and the FSSP-300 measurements is the sampling area, an instrumentspecific constant which can change when the alignment of the instrument changes. The sampling area of the PCASP-100X was determined in the laboratory by the synchronous measurement of the PCASP-100X and a CPC, which collected the air in the sample outlet of the PCASP-100X. Due to the geometry of the FSSP-300, the sampling area cannot be determined by the parallel operation of the spectrometer and a CPC. It is therefore known only within an estimated uncertainty of about $50 \%$. A common procedure for the determination and adjustment of the FSSP-300 sampling area is the comparison of a size distribution derived from the PCASP-100X with that derived from the FSSP300 in the overlap region of both instruments. The value for the sampling area was adjusted such that the number concentration measured with the FSSP-300 matched those measured with the PCASP-100X. To avoid artifacts due to humidity growth, the FSSP-300 intercomparison was done for a sequence with very low relative humidity $(<20 \%)$. The so determined value of the FSSP-300 sampling area was used for the analysis of the entire SAMUM-2 data set.

Another systematic uncertainty in the measurements from optical particle counters is the complex refractive index assumed for the derivation of size distributions in the respective averaging period. To constrain the refractive index for each constant altitude sequence, data from the $3 \lambda$ PSAP were used to derive the complex refractive index following the PSAP inversion method described in Petzold et al. (2009). The $3 \lambda$-PSAP 
Table 3. Dust and biomass burning layers and their average microphysical and optical properties from in situ measurements. For all quantities median and 3rd, 25th, 75th and 97th percentiles are listed

\begin{tabular}{|c|c|c|c|c|c|c|c|}
\hline & Median & $p_{03}$ & $p_{25}$ & $p_{75}$ & $p_{97}$ & Mean & $\sigma$ \\
\hline \multicolumn{8}{|l|}{ Layer characteristics } \\
\hline \multicolumn{8}{|l|}{ Altitude (m) } \\
\hline Mineral dust & 606 & 454 & 513 & 774 & 1427 & 705 & 256 \\
\hline Biomass burning & 2126 & 769 & 1419 & 3513 & 4197 & 2323 & 1033 \\
\hline \multicolumn{8}{|l|}{ Relative humidity (\%) } \\
\hline Mineral dust & 14 & 9 & 12 & 35 & 84 & 26 & 22 \\
\hline Biomass burning & 38 & 16 & 25 & 51 & 76 & 41 & 17 \\
\hline \multicolumn{8}{|c|}{ Stp-ambient conversion factor, $f_{\mathrm{STP}}$} \\
\hline Mineral dust & 0.858 & 0.793 & 0.837 & 0.868 & 0.889 & 0.852 & 0.024 \\
\hline Biomass burning & 0.737 & 0.604 & 0.644 & 0.782 & 0.841 & 0.724 & 0.071 \\
\hline \multicolumn{8}{|l|}{ Microphysical properties } \\
\hline \multicolumn{8}{|c|}{$N_{\text {nuc }}\left(\mathrm{cm}^{-3} \mathrm{stp}\right)$ : number concentration of particles between 4 and $10 \mathrm{~nm}$} \\
\hline Mineral dust & 0 & 0 & 0 & 20 & 2982 & 175 & 609 \\
\hline Biomass burning & 0 & 0 & 0 & 44 & 167 & 27 & 45 \\
\hline \multicolumn{8}{|c|}{$N_{10}\left(\mathrm{~cm}^{-3} \mathrm{stp}\right)$, number concentration of particles between $4 \mathrm{~nm}$ and $2.5 \mu \mathrm{m}$} \\
\hline Mineral dust & 833 & 406 & 568 & 1252 & 6068 & 1339 & 1380 \\
\hline Biomass burning & 1196 & 350 & 715 & 2401 & 4869 & 1678 & 1299 \\
\hline \multicolumn{8}{|c|}{$N_{\text {non-vol, } 10}\left(\mathrm{~cm}^{-3} \mathrm{stp}\right):$ number concentration of non-volatile particles between $4 \mathrm{~nm}$ and $2.5 \mu \mathrm{m}$} \\
\hline Mineral dust & 690 & 318 & 473 & 925 & 2817 & 883 & 613 \\
\hline Biomass burning & 1225 & 127 & 656 & 2505 & 4998 & 1673 & 1381 \\
\hline \multicolumn{8}{|c|}{$D_{\text {eff }}(\mu \mathrm{m})$ : effective diameter (diameter range: $0.01-30 \mu \mathrm{m}$ ) } \\
\hline Mineral dust & 2.47 & 1.40 & 1.88 & 2.79 & 3.44 & 2.41 & 0.63 \\
\hline Biomass burning & 1.06 & 0.67 & 0.82 & 1.28 & 1.83 & 1.08 & 0.29 \\
\hline \multicolumn{8}{|c|}{$D_{\text {eff,fine }}(\mu \mathrm{m})$ : fine mode effective diameter (diameter range: $\left.0.01-1 \mu \mathrm{m}\right)$} \\
\hline Mineral dust & 0.64 & 0.43 & 0.56 & 0.73 & 0.82 & 0.64 & 0.11 \\
\hline Biomass burning & 0.33 & 0.28 & 0.30 & 0.37 & 0.80 & 0.35 & 0.09 \\
\hline \multicolumn{8}{|c|}{$\operatorname{TSP}\left(\mu \mathrm{gm}^{-3} \mathrm{stp}\right):$ total mass concentrations } \\
\hline Mineral dust & 382 & 40 & 229 & 474 & 1147 & 409 & 290 \\
\hline Biomass burning & 123 & 13 & 74 & 236 & 453 & 159 & 119 \\
\hline \multicolumn{8}{|l|}{ Optical properties } \\
\hline \multicolumn{8}{|c|}{$\stackrel{\circ}{a}_{\text {ap }}:$ Ångström exponent of absorption } \\
\hline Mineral dust & 3.95 & 2.49 & 3.13 & 4.26 & 5.93 & 3.95 & 1.05 \\
\hline Biomass burning & 1.34 & 1.20 & 1.27 & 1.56 & 1.86 & 1.41 & 0.16 \\
\hline \multicolumn{8}{|c|}{$\sigma_{\text {ap }}(467 \mathrm{~nm})$ : absorption coefficient } \\
\hline Mineral dust & 5.8 & 1.6 & 3.0 & 6.8 & 8.5 & 5.3 & 2.1 \\
\hline Biomass burning & 16.0 & 0.9 & 7.5 & 29.1 & 51.0 & 19.5 & 14.6 \\
\hline \multicolumn{8}{|c|}{$\sigma_{\text {ap }}(530 \mathrm{~nm})$ : absorption coefficient } \\
\hline Mineral dust & 2.9 & 0.9 & 1.7 & 3.4 & 4.3 & 2.7 & 1.0 \\
\hline Biomass burning & 13.1 & 0.8 & 6.2 & 23.2 & 40.1 & 15.5 & 11.4 \\
\hline \multicolumn{8}{|c|}{$\sigma_{\text {ap }}(660 \mathrm{~nm})$ : absorption coefficient } \\
\hline Mineral dust & 1.0 & 0.0 & 0.4 & 1.4 & 2.1 & 1.0 & 0.6 \\
\hline Biomass burning & 10.2 & 0.6 & 4.8 & 17.4 & 29.8 & 11.7 & 8.5 \\
\hline \multicolumn{8}{|c|}{$m(467 \mathrm{~nm})$ : real part of the refractive index } \\
\hline Mineral dust & 1.55 & 1.55 & 1.55 & 1.55 & 1.56 & 1.550 & 0.002 \\
\hline Biomass burning & 1.57 & 1.56 & 1.57 & 1.58 & 1.59 & 1.574 & 0.007 \\
\hline \multicolumn{8}{|c|}{$k(467 \mathrm{~nm})$ : imaginary part of the refractive index } \\
\hline Mineral dust & 0.003 & 0.001 & 0.002 & 0.004 & 0.012 & 0.004 & 0.002 \\
\hline Biomass burning & 0.049 & 0.032 & 0.042 & 0.060 & 0.079 & 0.051 & 0.013 \\
\hline \multicolumn{8}{|c|}{$m(530 \mathrm{~nm})$ : real part of the refractive index } \\
\hline Mineral dust & 1.55 & 1.54 & 1.55 & 1.55 & 1.56 & 1.550 & 0.002 \\
\hline Biomass burning & 1.57 & 1.56 & 1.57 & 1.58 & 1.59 & 1.573 & 0.007 \\
\hline
\end{tabular}


Table 3. Cont'd

\begin{tabular}{|c|c|c|c|c|c|c|c|}
\hline & Median & $p_{03}$ & $p_{25}$ & $p_{75}$ & $p_{97}$ & Mean & $\sigma$ \\
\hline \multicolumn{8}{|c|}{$k(530 \mathrm{~nm})$ : imaginary part of the refractive index } \\
\hline Mineral dust & 0.002 & 0.000 & 0.001 & 0.003 & 0.008 & 0.003 & 0.002 \\
\hline Biomass burning & 0.042 & 0.025 & 0.037 & 0.052 & 0.071 & 0.045 & 0.011 \\
\hline \multicolumn{8}{|c|}{$m(660 \mathrm{~nm})$ : real part of the refractive index } \\
\hline Mineral dust & 1.55 & 1.54 & 1.54 & 1.55 & 1.55 & 1.546 & 0.002 \\
\hline Biomass burning & 1.57 & 1.56 & 1.57 & 1.57 & 1.59 & 1.571 & 0.007 \\
\hline \multicolumn{8}{|c|}{$k(660 \mathrm{~nm})$ : imaginary part of the refractive index } \\
\hline Mineral dust & 0.001 & 0.000 & 0.000 & 0.002 & 0.005 & 0.001 & 0.001 \\
\hline Biomass burning & 0.040 & 0.019 & 0.035 & 0.053 & 0.074 & 0.043 & 0.013 \\
\hline
\end{tabular}

Fig. 5. Composite size distribution of biomass burning aerosol from $\mathrm{CPC}$, PCASP-100X and FSSP-300 measurements (symbols) for level L04 on flight 080119c. The grey line represents the parametrized fit with four log-normal modes.

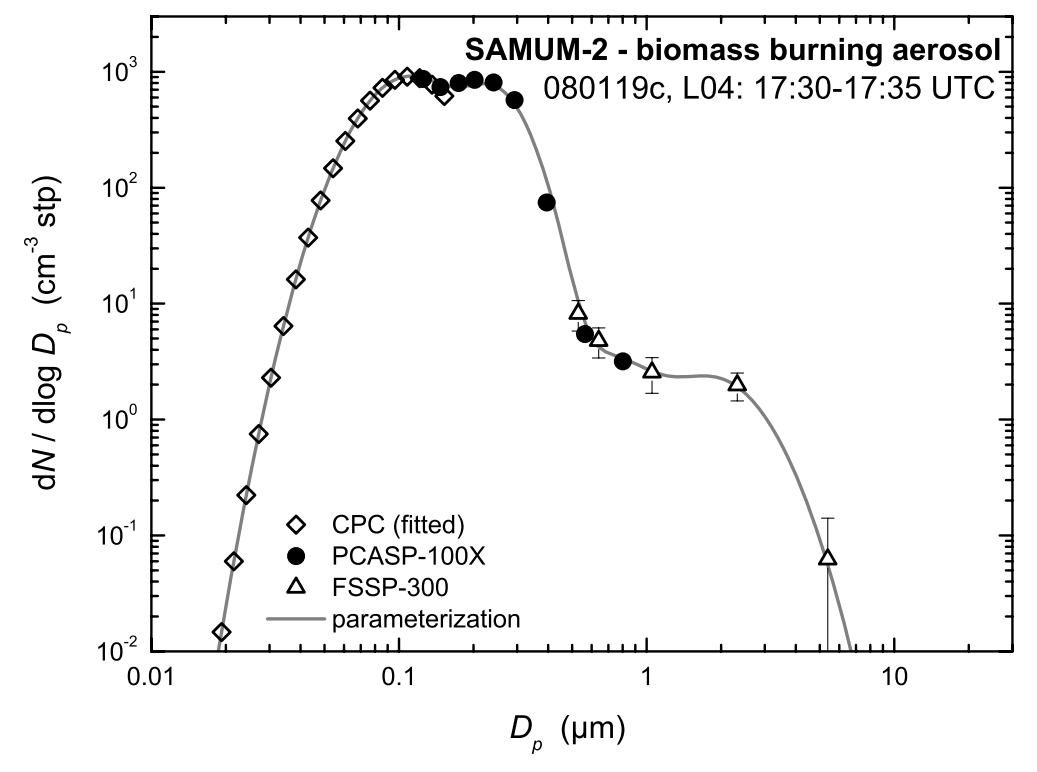

primarily measures the particle absorption coefficient at three different wavelengths. This data can be used together with size distribution measurements to invert the complex refractive index and the effective chemical composition of an aerosol. Since the method and the analysis uncertainties are discussed in detail by Petzold et al. (2009; 2011), we repeat only the most important aspects of the PSAP inversion. Based on the $3 \lambda$-PSAP correction scheme (Virkkula et al., 2005; Virkkula, 2010), the applied inversion algorithm simulates the response of the $3 \lambda$ PSAP to the sampled aerosol. Absorption and scattering coefficients are calculated with Mie theory from the size distribution measured by the PCASP-100X under the assumption of a complex refractive index. The complex refractive index is then optimized in an iterative process to match the PSAP's responses at all three wavelengths within a deviation of $3 \%$. Based on the optimized refractive index, the effective chemical composition of the particles is described as a linear combination of three chemical components: a solely light scattering component $\left(\mathrm{SiO}_{2}\right)$, a light absorbing component with a strong spectral dependence of the refractive index (hematite, $\mathrm{Fe}_{2} \mathrm{O}_{3}$ ), and a component with spec- trally flat refractive index (black carbon). Note that the inversion of the real part of the refractive index is ambiguous. However, the three-component model described above constrains the real part of the refractive index. The refractive indices used for the analysis of OPC data (measurement wavelength: $632 \mathrm{~nm}$ ) are summarized in Table 3. We want to point out here that the $3 \lambda$ PSAP instrument is situated inside the cabin of the Falcon. Therefore, the refractive indices derived from the PSAP measurements are only valid for particles smaller than about $2.5 \mu \mathrm{m}$. From the analysis of single mineral dust particles collected during the flights and at the ground (Kandler et al., 2011; Lieke et al., 2011), we know that the refractive index is strongly size dependent. Particles larger than 2-3 $\mu \mathrm{m}$ show less absorption than smaller particles. In the case of mineral dust particles, absorption decreases by more than a factor of 3 to almost zero for particles larger than 2-3 $\mu \mathrm{m}$ (Kandler et al., 2011). For these reasons, we take a refractive index with an absorbing component as derived from the $3 \lambda$ PSAP for the size range below 2-3 $\mu \mathrm{m}$ size. For larger particles, we assume a refractive index of $1.55+0 \mathrm{i}$ to be appropriate. The effect of an uncertainty in the 
imaginary part of the refractive index on the derived mineral dust size distribution was assessed in detail by Weinzierl et al. (2009) who used the effective diameter $D_{\text {eff }}$ (Hansen, 1971; Hansen and Travis, 1974) as a measure for the particle size distribution. As a result of the set-up of the FSSP-300 channels, the sensitivity of the instrument to the imaginary part of the refractive index increases with increasing particle size. To estimate the upper limit of the effect of the uncertainty of the refractive index, Weinzierl et al. (2009) used a dust size distribution that extended to $D_{\mathrm{p}} \sim$ $40 \mu \mathrm{m}$ and varied the imaginary part of the refractive index. A single refractive index was used for the derivation of the complete mineral dust size distribution and it was shown that an uncertainty of $\pm 10 \%, \pm 20 \%$ and $\pm 50 \%$ in the imaginary part of the refractive index caused a change in the effective diameter $D_{\text {eff }}$ of 3-4\%, 3-5\% and 5-8\%, respectively. These numbers can be regarded as an upper limit for the uncertainty because a dust size distribution with a significant number of super-micron particles was chosen for this analysis. Furthermore, it was assumed that the complete size distribution contains absorbing particles. In contrast, for the data presented in this study, we used a size dependent refractive index as described above. For one case, the sensitivity of the derived $D_{\text {eff }}$ on the assumed refractive index was assessed using a size-dependent refractive index. We took a sequence in mineral dust and assumed three different refractive indices $(1.55+0 \mathrm{i}, 1.55+0.0019 \mathrm{i}$ and $1.55+0.0044 \mathrm{i})$ to derive the size distribution of particles smaller than $1 \mu \mathrm{m}$. For larger particles a non-absorbing refractive index $(1.55+0 \mathrm{i})$ was assumed according to the chemical analyses. In the case investigated, the $D_{\text {eff }}$ changed less than $1 \%$.

To describe particle size distributions in optical models, the size distributions were parametrized by fitting multimodal lognormal distributions. Four log-normal modes, each of them described by the integral particle concentration of each lognormal mode $\left(N_{\text {mode }, j}\right)$, the median diameter $\left(C M D_{\text {mode }, j}\right)$ and the geometric standard deviation $\left(G S D_{\text {mode }, j}\right)$, are sufficient to parametrize the data. The quality of the parametrizations is controlled by comparing effective diameter calculated directly from the inverted data $D_{\text {eff }}($ data $)$ and from the parametrization $D_{\text {eff }}$ (mode) using the Hatch-Choate conversion equations (Hatch and Choate, 1929). The parametrizations were regarded as adequate when the deviation between $D_{\text {eff }}($ data $)$ and $D_{\text {eff }}$ (mode) was smaller than about $5 \%$. On average, the deviation between parametrization and data is $3 \%$ (see Table A1). In one case it was not possible to appropriately fit the measured size distribution with the combination of four log-normal modes. Figure 4 shows an example for the fit of a size distribution.

Unless stated otherwise, all particle number concentration and size distribution data are given for standard temperature and pressure conditions STP $(273.15 \mathrm{~K}, 1013.25 \mathrm{hPa})$. The STP concentration data correspond to mixing ratios, which are independent of ambient pressure and temperature during the measurement. Data calculated for STP conditions can be converted to ambient conditions by multiplication with $f_{\text {STP }}$ given in Tables 3 and A1. For the calculation of optical properties, ambient size distributions and absorption coefficients have to be used.

\subsection{Aerosol type classification}

The aerosol type at the individual constant altitude sequences was determined on the basis of the in situ and HSRL measurements. We know from recent field campaigns that aerosols can be classified based on the measurements of two aerosol-specific quantities (Tesche et al., 2009; Groß et al., 2011b; Tesche et al., 2011a): the lidar ratio and the aerosol linear depolarization ratio. ${ }^{1}$ Analyses of both quantities showed that characteristic values can be attributed to the different aerosol types. A particle depolarization ratio of $31 \pm 3 \%$ at $532 \mathrm{~nm}$ is characteristic for Saharan dust (Freudenthaler et al., 2009). In contrast, aged Siberian and Canadian forest fire smoke layers typically show depolarization ratios of 2-3\% (Müller et al., 2005). However, the lifting of soil material within burning areas can result in particle depolarization ratios larger than 10\% (Fiebig et al., 2002; Tesche et al., 2009). As we will show later (see Section 3.4 and Fig. 10), the tropical biomass burning layers investigated were not pure biomass burning layers. They always contained some large coarse mode dust particles influencing the observed depolarization ratios. Therefore, it was necessary to use additionally an in situ parameter, the Ångström exponent of absorption $\stackrel{\leftrightarrow}{a}$ ap $_{\text {, }}$, to make the decision on the aerosol type. The Ångström exponent of absorption, describes the wavelength dependence of the absorption coefficient. It has been shown earlier (e.g. Petzold et al., 2009) to be a good measure for aerosol types and aerosol source regions. In our case, $\stackrel{\circ}{a p}_{\text {ap }}$ is calculated from the $3 \lambda$ PSAP measurements as follows

$$
\stackrel{\circ}{a p}_{\text {ap }}=-\frac{\ln \frac{\sigma_{\mathrm{ap}}(467 \mathrm{~nm})}{\sigma_{\mathrm{ap}}(660 \mathrm{~nm})}}{\ln \frac{467 \mathrm{~nm}}{660 \mathrm{~nm}}} .
$$

For pure black carbon, a value of 1.0 is expected for $\stackrel{\circ}{a}_{\text {ap }}$ (Bohren and Huffman, 1983). The analysis of $\stackrel{a}{a p}_{\text {ap }}$ for the SAMUM-1 data set revealed values between 3.1 and 5.0 for fresh dust depending on the dust source region (Petzold et al., 2009). Laboratory studies by Linke et al. (2006) yielded values between 4.2 and 5.3 for mineral dust.

In this study, all constant altitude sequences are classified based on their location in the parameter space of depolarization ratio, lidar ratio, and Ångström exponent. Aerosol layers showing an absorption Ångström exponent larger than 2 and a depolarization-ratio larger than $\sim 17 \%$ were classified as mineral

\footnotetext{
${ }^{1}$ In this study, the term 'linear particle depolarization ratio' is abbreviated as 'particle depolarization ratio' or 'depolarization ratio'.
} 


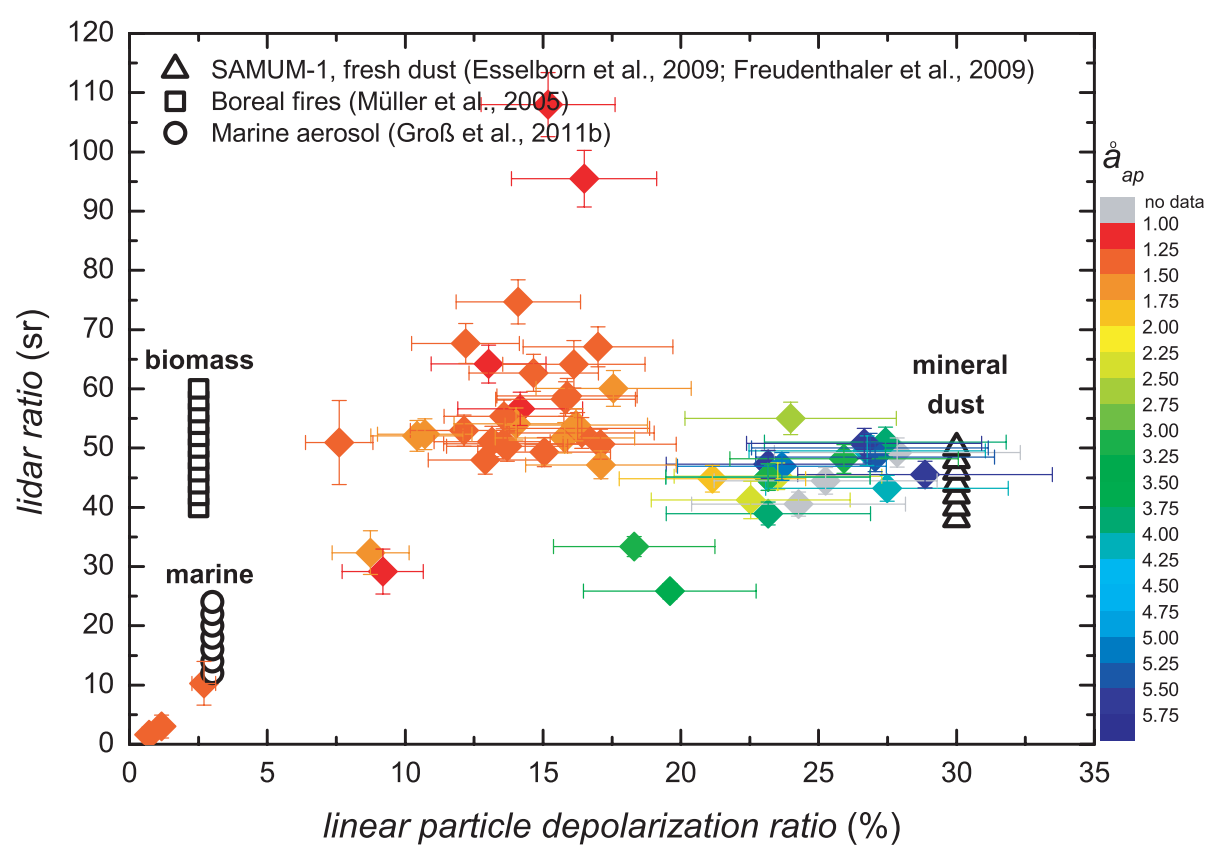

Fig. 6. Classification of the individual constant altitude sequences on the basis of HSRL and in situ measurements. The absorption Ångström

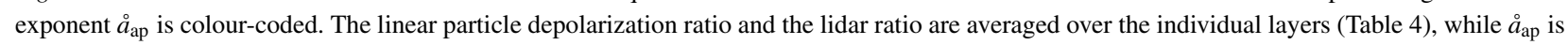
taken from the corresponding constant altitude sequences.

dust aerosol. Aerosol layers showing an absorption Ångström exponent between 1 and 2 and depolarization ratios smaller than $16 \%$ were classified as tropical biomass burning (biomass dominated) layer. ${ }^{2}$ Layers with depolarization ratios below $9 \%$ and a small lidar ratio below $\sim 30 \mathrm{sr}$ were considered to be mixtures of marine or anthropogenic pollution aerosol and dust. Figure 6 shows the results of the aerosol classification. It can be seen that the mixing of different aerosol components in the parameter space of depolarization ratio and lidar ratio follows rather a curve than a straight line. These mixing curves are theoretically derived in Groß et al. (2011b). Altogether, 65 constant altitude sequences were investigated in detail: 31 sequences were classified as biomass burning layers, 24 as mineral dust layers, and 10 as mixtures (dust+marine, dust+anthropogenic pollution, marine+anthropogenic pollution). The locations of the constant altitude sequence are shown in Fig. 3. To validate the results of the aerosol classification, backward trajectories were calculated with LAGRANTO (Wernli and Davies, 1997; Wernli, 1997; see Section 4.2) for all 65 aerosol layers investigated. Examples of backward trajectories are shown in Figs. 18, 19 and 21. The trajectories confirm the aerosol classification based on HSRL and in situ measurements.

\footnotetext{
${ }^{2}$ During SAMUM-2, all tropical biomass burning layers investigated were mixtures because they also contained some large dust particles. In the following, we refer to those mixtures as '(tropical) biomass burning layers'.
}

\section{Results}

\subsection{Vertical structure of the atmosphere in the Cape Verde region during $S A M U M-2$}

During the SAMUM-2 field phase, strong dust activity in the Sahara region and strong biomass burning emissions in Western Africa lead to regular transport of dust and biomass burning plumes into the study region. The advection of aerosol layers from different origins resulted in complex aerosol structures with different layers. Figure 7 illustrates the complex aerosol structure over the Atlantic Ocean during SAMUM-2. The plot shows the HSRL backscatter ratio at $532 \mathrm{~nm}$. The backscatter ratio is defined as the ratio of total backscatter (i.e. molecular plus particle) coefficient and the molecular backscatter coefficient (e.g. Freudenthaler et al., 2009). The data were taken during the flight from Tenerife to Cape Verde on 19 January 2008. In Fig. 8 the corresponding vertical profile of in situ data is shown for the descent over Praia (Cape Verde Islands). In this case, a mineral dust layer of about $1 \mathrm{~km}$ geometrical depth was underlying a biomass burning layer which covered the altitude range between 1.7 and $6 \mathrm{~km}$ a.s.l. Both layers show enhanced concentrations of accumulation mode and coarse mode particles. However, the biomass burning layer had only a few large super-micron particles, while the number concentration of those particles was strongly enhanced in the mineral dust layer. The absorption coefficient $(530 \mathrm{~nm})$ was, with values between 2.7 and $3.6 \mathrm{Mm}^{-1}$, larger in the biomass burning layer than in the mineral dust layer $\left(1.5 \mathrm{Mm}^{-1}\right)$. In contrast, the $D_{\text {eff }}$ in the biomass burning layer 


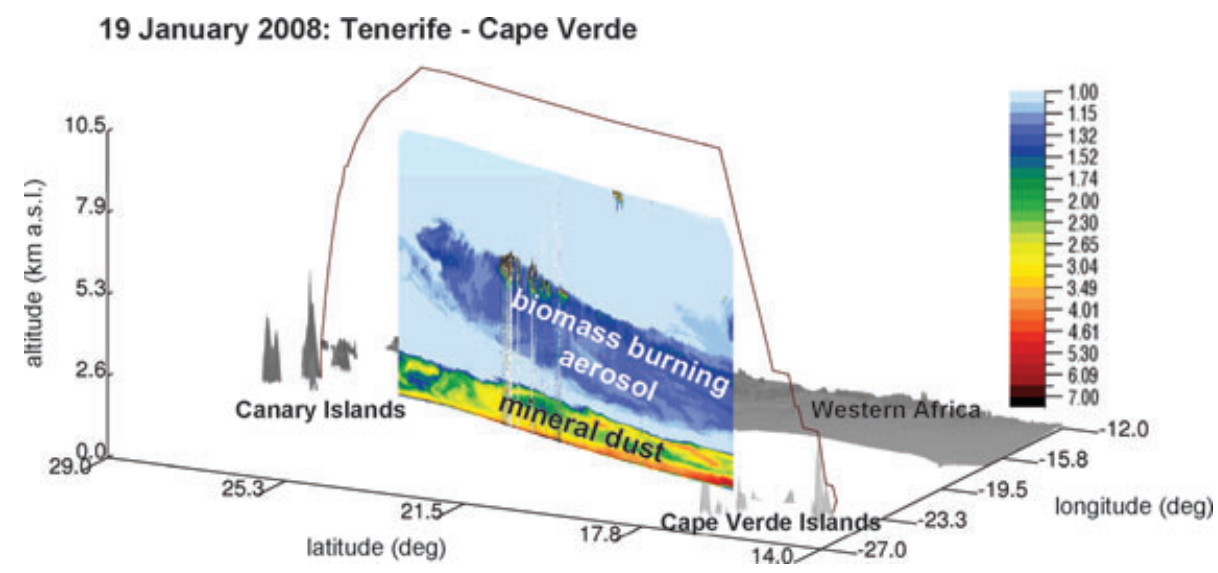

Fig. 7. High Spectral Resolution Lidar (HSRL) image recorded on 19 January 2008 (color-coded is the backscatter ratio at $532 \mathrm{~nm}$ ). The image illustrates the complex aerosol structure over the Atlantic Ocean during SAMUM-2. Between about 0.3 and $1.3 \mathrm{~km}$ altitude, a mineral dust plume from the Sahara is present, while the atmosphere between 2 and $6 \mathrm{~km}$ altitude is influenced by a tropical biomass burning plume from southern West Africa. The aerosol plumes extend over a horizontal distance of more than $1000 \mathrm{~km}$.
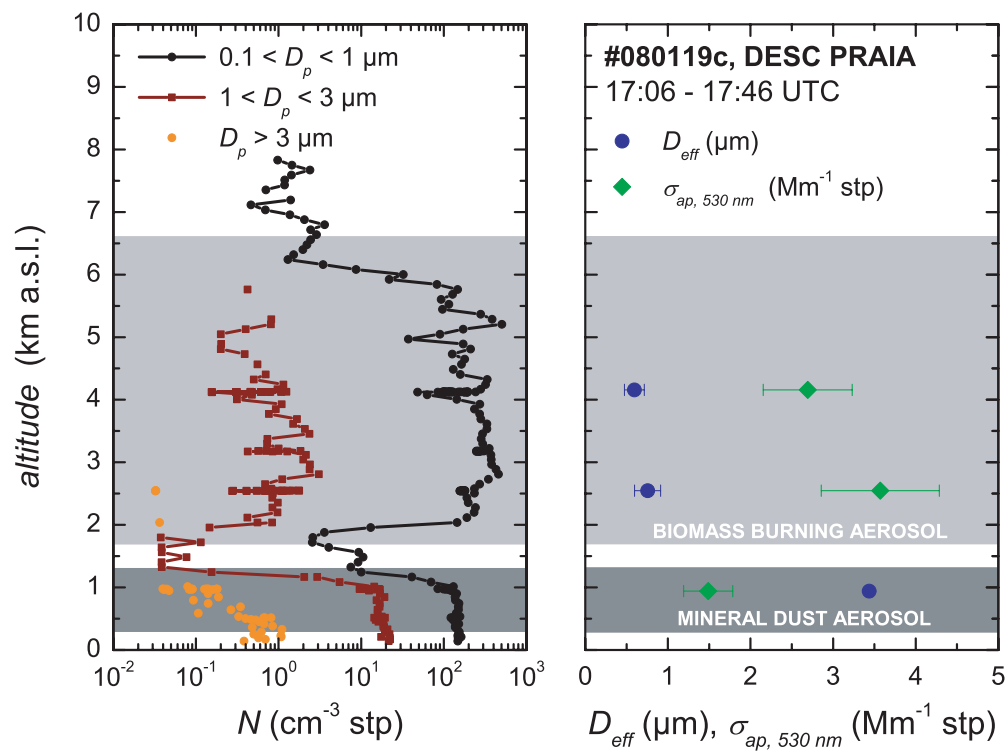

Fig. 8. Vertical layering of the atmosphere above Praia (Santiago, Cape Verde) on 19 January 2008. The left-hand panel shows profiles of particle number concentration for STP conditions in the size range of $0.1<D_{\mathrm{p}}$ $<1 \mu \mathrm{m}$ (black line), $1<D_{\mathrm{p}}<3 \mu \mathrm{m}$ (brown line) and $D_{\mathrm{p}}>3 \mu \mathrm{m}$ (orange symbols). In the right-hand panel, the effective diameter $D_{\text {eff }}$ (blue symbols) and the absorption coefficient $\sigma_{\text {ap }}$ at $530 \mathrm{~nm}$ (green symbols) is shown. The grey shaded areas show the vertical extent of the biomass burning and the mineral dust layers as derived from the HSRL measurements (Figs. 7 and 9).

was, with values of 1.45 and $0.75 \mu \mathrm{m}$, much smaller than the $D_{\text {eff }}$ measured in the mineral dust $(3.44 \mu \mathrm{m})$.

A complex aerosol structure was detected in every science flight during SAMUM-2. Figure 9 shows the time series of the aerosol linear depolarization ratio measured with the HSRL at $532 \mathrm{~nm}$. For every SAMUM-2 flight, a snapshot of 10-90 min duration is plotted as a function of travel distance and time. In this representation, different colours indicate different aerosol types. Red and orange colors correspond to mineral dust aerosol (depolarization ratios around $20-30 \%$ ), green and yellow colours show biomass burning layers $(\sim 10-17 \%)$. It can be seen from Fig. 9 that the mineral dust layers showed a rather homogeneous structure in most cases. In contrast, the internal structure of the biomass burning layers is more complicated: in many cases a lot of internal layering is visible within small horizontal and vertical distances. To derive mean lidar properties of the vertical structure seen in the HSRL measurements, we select in total 33 sequences from the HSRL data where the vertical structure of the aerosol layers is sufficiently homogeneous. Based on the measurements of depolarization and extinction we define between one and three distinct aerosol layers for each sequence. The medians and percentiles of the main lidar-quantities extinction coefficient, particle linear depolarization, lidar ratio and AOD are given in Table 4. Detailed information on all layers can be found in Appendix Table A2. On average, the dust plumes had a depth of $1.3 \pm 0.4 \mathrm{~km}$ and were situated below $2 \mathrm{~km}$ a.s.1., while the central African biomass burning layers had an average depth of $2.0 \pm 1.1 \mathrm{~km}$ covering the altitude range between 2 and $4-5 \mathrm{~km}$. 

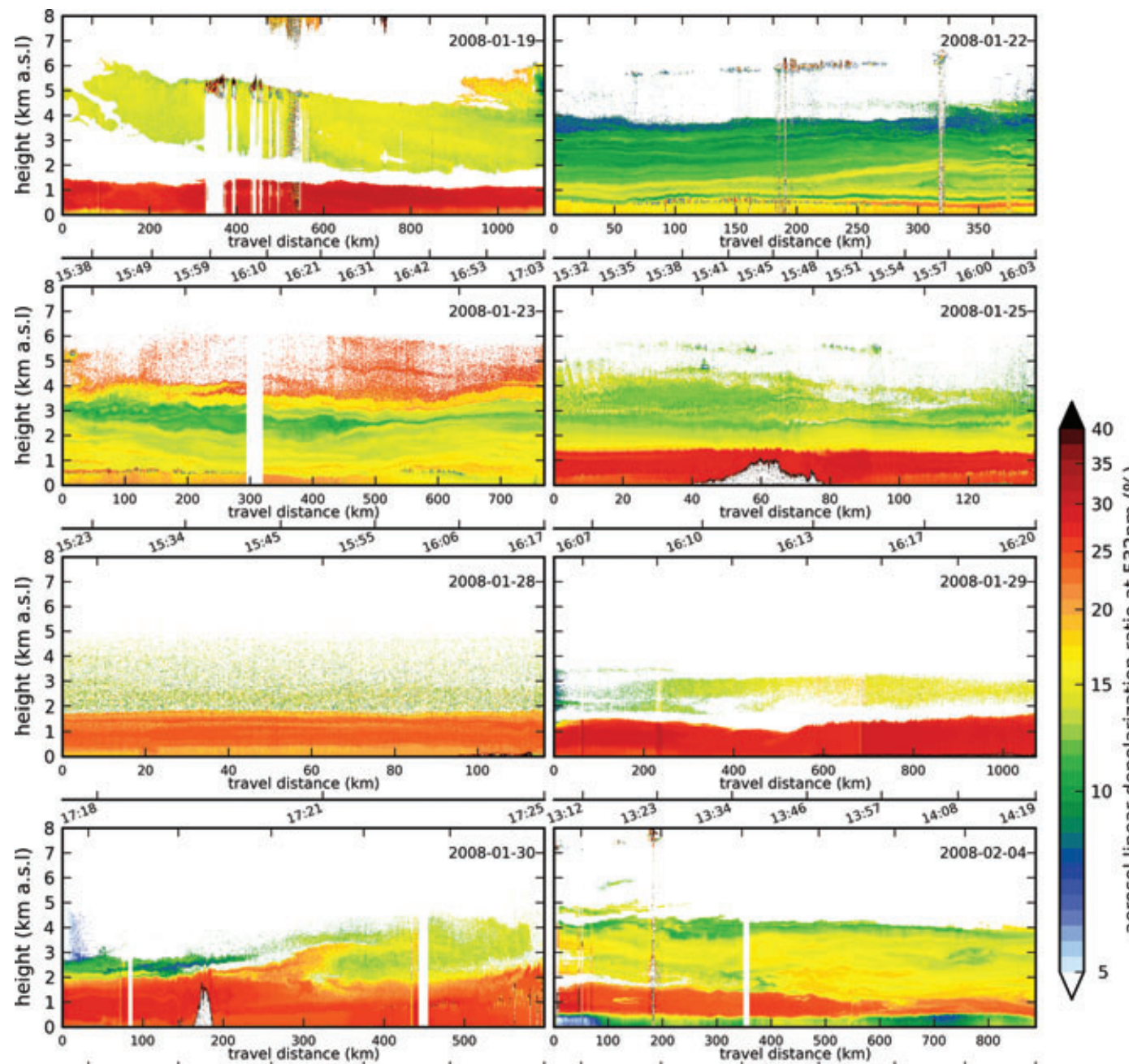

${ }^{35}{ }^{40}$ है

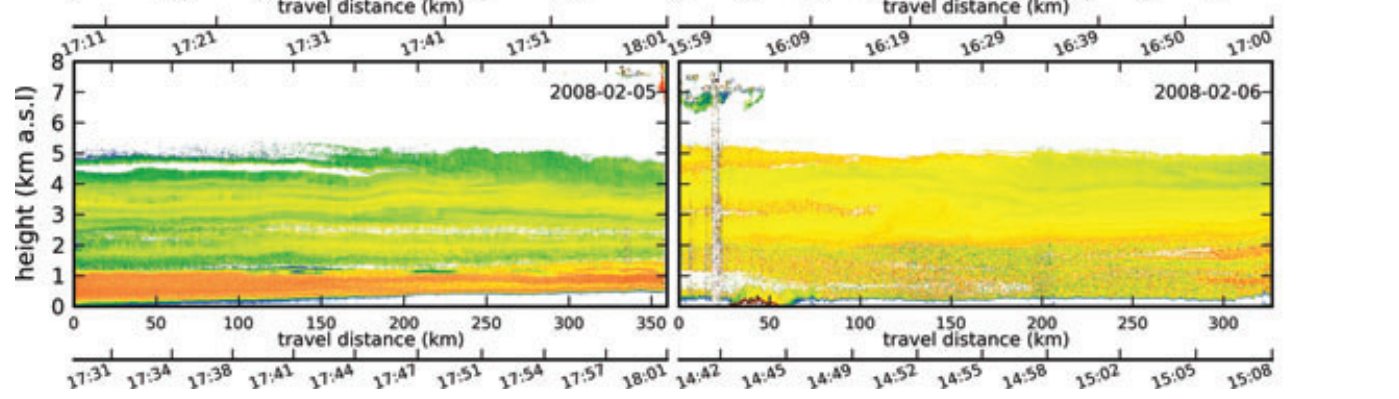

Fig. 9. Selected time series of the particle linear depolarization ratio (in the following abbreviated as depolarization ratio) measured with the HSRL at $532 \mathrm{~nm}$. For every flight one representative cross section is shown. The different colours can be interpreted as different aerosol types. Orange and reddish colours (depolarization ratio 20-30\%) indicate mineral dust aerosol, yellow and green colours show biomass burning layers

(depolarization ratio $\sim 10-15 \%$ ). Blue colours indicate aerosols with low depolarization ratios $(\sim 0-5 \%)$ such as marine or anthropogenic pollution aerosol. On the $x$-axis the travel distance and UT times of the flight track during the HSRL-measurement are shown.

Figure 10 shows averaged ${ }^{3}$ vertical profiles of aerosol number concentration in three different size ranges as derived from the in

\footnotetext{
${ }^{3}$ Averaged over the 25 vertical profiles measured during SAMUM-2. Only measurements outside of clouds were considered.
}

situ measurements. The total fine mode aerosol $(0.01-2.5 \mu \mathrm{m})$ does not indicate an increase in aerosol number concentration at any specific altitudes, but the variability between the $3 \mathrm{rd}$ and 97th percentile values is slightly enhanced in the lowermost part of the troposphere. In contrast, the median number concentration 
Table 4. Dust and biomass burning layers and their average properties from HSRL measurement (532 nm). For all quantities median and 3rd, 25rth, 75th and 97th percentiles are listed

\begin{tabular}{|c|c|c|c|c|c|}
\hline & Median & $p_{03}$ & $p_{25}$ & $p_{75}$ & $p_{97}$ \\
\hline \multicolumn{6}{|l|}{ Aerosol optical depth } \\
\hline Mineral dust & 0.23 & 0.03 & 0.13 & 0.35 & 0.58 \\
\hline Biomass burning & 0.09 & 0.01 & 0.02 & 0.14 & 0.50 \\
\hline \multicolumn{6}{|c|}{ Extinction coefficient $\left(\mathrm{km}^{-1}\right)$} \\
\hline Mineral dust & 0.18 & 0.05 & 0.13 & 0.26 & 0.40 \\
\hline Biomass burning & 0.04 & 0.01 & 0.02 & 0.09 & 0.15 \\
\hline \multicolumn{6}{|c|}{ Particle linear depolarization ratio (\%) } \\
\hline Mineral dust & 22.1 & 17.2 & 21.3 & 23.0 & 26.3 \\
\hline Biomass burning & 13.1 & 6.3 & 11.8 & 15.0 & 16.4 \\
\hline \multicolumn{6}{|l|}{ Lidar ratio (sr) } \\
\hline Mineral dust & 42.3 & 33.4 & 40.7 & 45.5 & 52.4 \\
\hline Biomass burning & 56.1 & 45.0 & 50.0 & 61.8 & 93.0 \\
\hline
\end{tabular}

of non-volatile particles (dust, sea salt, black carbon or crustal material) increases from $195 \mathrm{~cm}^{-3}$ (3rd and 97th percentiles: $\left.p_{03}=39 \mathrm{~cm}^{-3} ; p_{97}=266 \mathrm{~cm}^{-3}\right)$ in the free troposphere by a factor 3.5 to $679 \mathrm{~cm}^{-3}\left(p_{03}=409 \mathrm{~cm}^{-3} ; p_{97}=1610 \mathrm{~cm}^{-3}\right)$ in the biomass burning layers at altitudes between 4.3 and $1.6 \mathrm{~km}$ a.s.l. For the dust layers between 1.6 and $\sim 0.5 \mathrm{~km}$ a.s.1. the median number concentration drops only slightly to $674 \mathrm{~cm}^{-3}\left(p_{03}=63\right.$ $\mathrm{cm}^{-3} ; p_{97}=757 \mathrm{~cm}^{-3}$ ). From the total and non-volatile particle number concentration, the fraction of non-volatile particles $\left(f_{\text {non-vol }}\right)$ was calculated. While the median $f_{\text {non-vol }}$, is $80 \%\left(p_{03}\right.$ $\left.=78 \% ; p_{97}=88 \%\right)$ in the desert dust plumes, it decreases to $74 \%\left(p_{03}=48 \% ; p_{97}=87 \%\right)$ in the biomass burning plumes. As expected, $f_{\text {non-vol }}$ is much lower outside of biomass burning and mineral dust layers with values of $32 \%\left(p_{03}=22 \% ; p_{97}=39 \%\right)$. As already seen for 19 January 2008 both, biomass burning and mineral dust plumes show enhanced values of accumulation mode aerosol (Fig. 10c). Although the number concentration of large super-micrometre particles was much more enhanced in the mineral dust plumes, the biomass burning layers still showed some large super-micron particles (Fig. 10d). In comparison to the mineral dust layers, the biomass burning layers showed larger variability in number concentration from flight to flight and also on individual constant altitude sequences.

\subsection{Horizontal structure of dust and biomass burning aerosol layers and the influence of islands during SAMUM-2}

The HSRL data not only allow for the characterization of the vertical structure of the atmosphere, they give also insight into the horizontal structure and variation of the aerosol layers. The ground-based stationary lidar systems at Praia airport show that the aerosol layer structure was fairly stable in time for sev- eral days (Groß et al., 2011b; Tesche et al., 2011b). The HSRL measurements over the open ocean show a homogeneous stratification of aerosol layers with similar extent over large distances. However, in the vicinity of the Cape Verde islands, strong spatial variations in layer properties occur which are caused by the local orography and heat flows disturbing the flow of air over the ocean. The variation in vertical aerosol profiles resulting from the islands is visible in some of the panels in Fig. 9 and is further illustrated in Fig. 11. Here the left panel shows the backscatter ratio at $532 \mathrm{~nm}$ measured during an overpass flight over the Santiago island on 25 January 2008. On that day the Falcon crossed the island from the southeast in northwestern direction. The right panel shows the vertical mean profiles for the extinction coefficient extracted for the two shaded intervals in the left panel. Interval 1 is located around Praia airport where a simultaneous measurement was taken with the ground-based lidar system MULIS (Groß et al., 2011b). The extinction profile seen by MULIS is shown in red in the right panel of Fig. 11, while the two HSRL profiles are shown in blue and green. A detailed study of the island effects is presented in Engelmann et al. (2011). They find that on this day the wind near the surface came from northeast to east (i.e. almost perpendicular to the flight direction). The air masses carrying the lower-level dust layers seen at Praia airport were therefore only affected by the neighbouring island Maio at a distance of about $50 \mathrm{~km}$. The averaging interval 2 lies in the zone where the warmer surface of the larger Santiago island leads to substantial turbulent mixing of the aerosol layers in altitudes below $\sim 2 \mathrm{~km}$. (Note that the orography of the island plays a minor role in this case because the air masses seen at interval 2 did not previously pass over the high mountain top of Pico da Antonia seen in this plot.) For the scope of this work it is important to note that the data used for direct comparison of optical properties derived from in situ and lidar measurements have to be chosen carefully. The geographical proximity of measurement sites is in most cases more important than the temporal proximity of the measurements.

\subsection{Microphysical and optical properties of Saharan mineral dust layers}

In this study, we investigated 24 dust layers, a summary of microphysical and optical properties derived for those sequences is given in Table 3. The dust layers showed a median absorption Ångström exponent $\stackrel{\circ}{a p}_{\text {ap }}$ of $3.95\left(p_{03}=2.49 ; p_{97}=5.93\right)$. The scatter plot of the absorption coefficient $\sigma_{\text {ap }}$ as a function of the

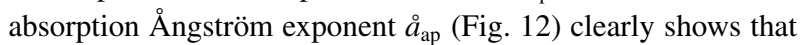
the dust layers are only weakly absorbing. The median absorption coefficients at $530 \mathrm{~nm}$ was found to be $\sigma_{\text {ap }}=2.9 \mathrm{Mm}^{-1}$ $\left(p_{03}=0.9 \mathrm{Mm}^{-1} ; p_{97}=4.3 \mathrm{Mm}^{-1}\right)$ The median AOD of the dust layers was $0.23\left(p_{03}=0.03 ; p_{97}=0.58\right)$. In the dust layers, no nucleation mode particles were found. The total particle size distribution of mineral dust aerosol measured during SAMUM-2 is 
Fig. 10. Average of 25 vertical profiles of aerosol number concentration measured during SAMUM-2: median number concentrations (bold lines) of particles with diameters $D_{\mathrm{p}}$ (a) $0.01<D_{\mathrm{p}}<2.5 \mu \mathrm{m}$ (total aerosol), (b) $0.01<D_{\mathrm{p}}<2.5 \mu \mathrm{m}$ (non-volatile aerosol), (c) $0.1<D_{\mathrm{p}}<1 \mu \mathrm{m}$ and (d) $D_{\mathrm{p}}>3 \mu \mathrm{m}$. The black line indicates the median value. The light grey shaded areas represent the range within $3 \mathrm{rd}$ and 97 th percentile values, and the dark grey areas represent the range within the 25 th and 75 th percentile values. All numbers are given for STP conditions.

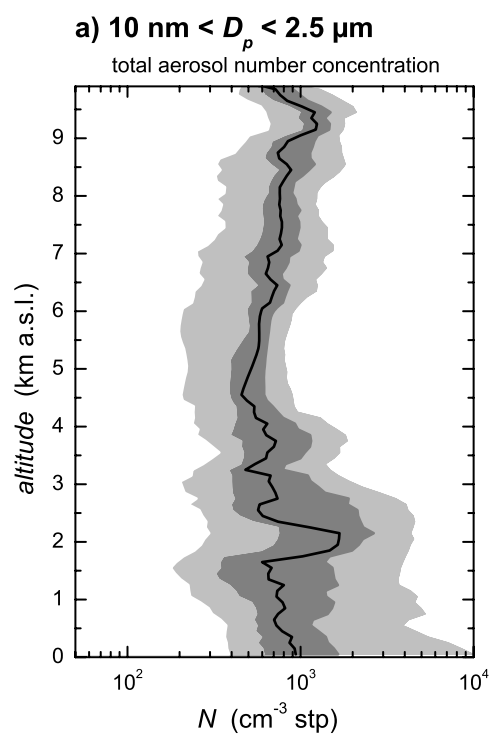

c) $0.1<D_{p}<1 \mu \mathrm{m}$

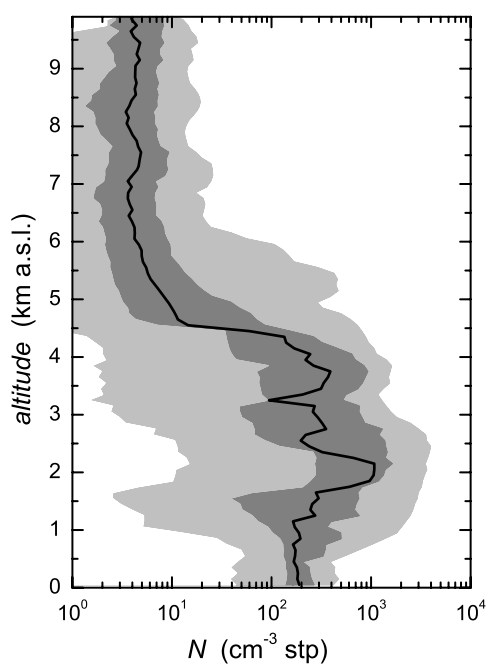

b) $10 \mathrm{~nm}<D_{p}<2.5 \mu \mathrm{m}$

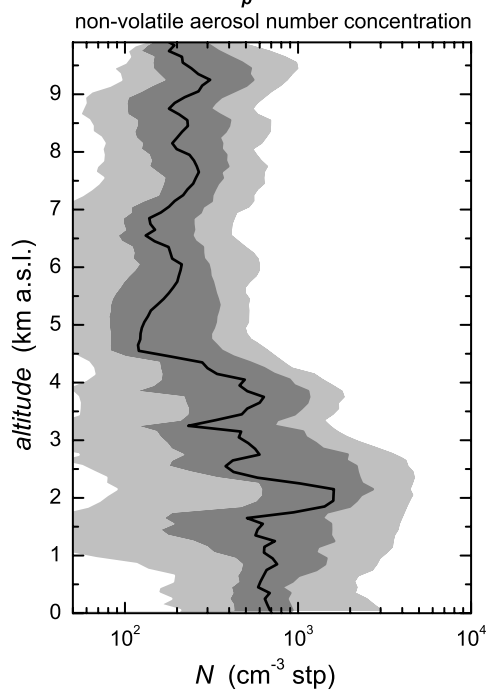

d) $D_{p}>3 \mu \mathrm{m}$

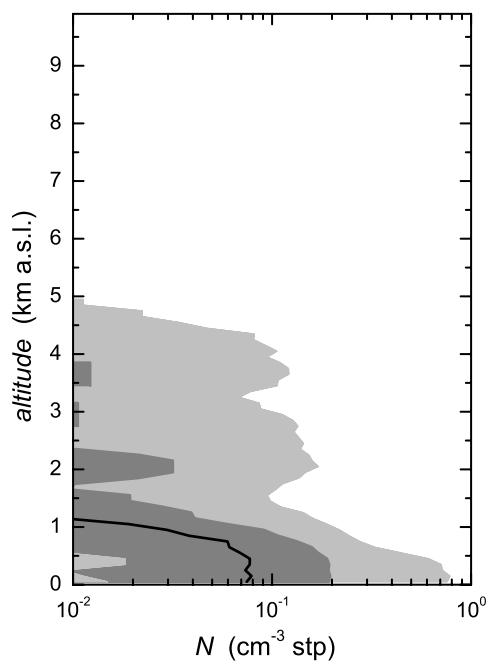

shown in Fig. 13. For comparison, the envelope of mineral dust size distributions measured during SAMUM-1 is also indicated. While the Aitken mode (mode 1 in Table 5) observed during SAMUM-1 is very similar to that observed during SAMUM-2, a clear difference can be seen for the coarse mode particles. Although still a significant number of coarse mode particles is present during SAMUM-2, no particles larger than $30 \mu \mathrm{m}$ are observed in contrast to SAMUM-1 (see also Table 6). From the size distribution, $D_{\text {eff }}$ was calculated for all dust sequences. Results are shown in Fig. 14. The median $D_{\text {eff }}$ in the dust layers was $2.47 \mu \mathrm{m}\left(p_{03}=1.40 \mu \mathrm{m} ; p_{97}=3.44 \mu \mathrm{m}\right)$ during SAMUM2 . The effective diameters observed during SAMUM-2 are thus significantly smaller than the $D_{\text {eff }}$ observed during SAMUM-1, which showed a median value of $5.86 \mu \mathrm{m}\left(p_{03}=2.45 \mu \mathrm{m}\right.$; $\left.p_{97}=12.19 \mu \mathrm{m}\right)$.

\subsection{Microphysical and optical properties of tropical biomass burning aerosol from savannah fires}

Besides mineral dust layers, we analysed 31 biomass burning aerosol layers. The microphysical and optical properties of those layers are also summarized in Table 3 . We found the median value of $\stackrel{a}{\text { ap }}_{\text {ap }}$ to be $1.34\left(p_{03}=1.20 ; p_{97}=1.86\right)$. The biomass burning layers were strongly absorbing with a median absorption coefficient of $13.1 \mathrm{Mm}^{-1}\left(p_{03}=0.8 \mathrm{Mm}^{-1} ; p_{97}=40.1 \mathrm{Mm}^{-1}\right)$ at $530 \mathrm{~nm}$ (see also Fig. 12). The median AOD of the biomass burning layers was $0.09\left(p_{03}=0.01, p_{97}=0.50\right)$. In nearly all layers, nucleation mode particles were absent. Figure 15 displays size distributions of the total aerosol measured in biomass burning layers during SAMUM-2. For comparison, a size distribution measured in aged Canadian boreal forest fire aerosol after 6-9 d 


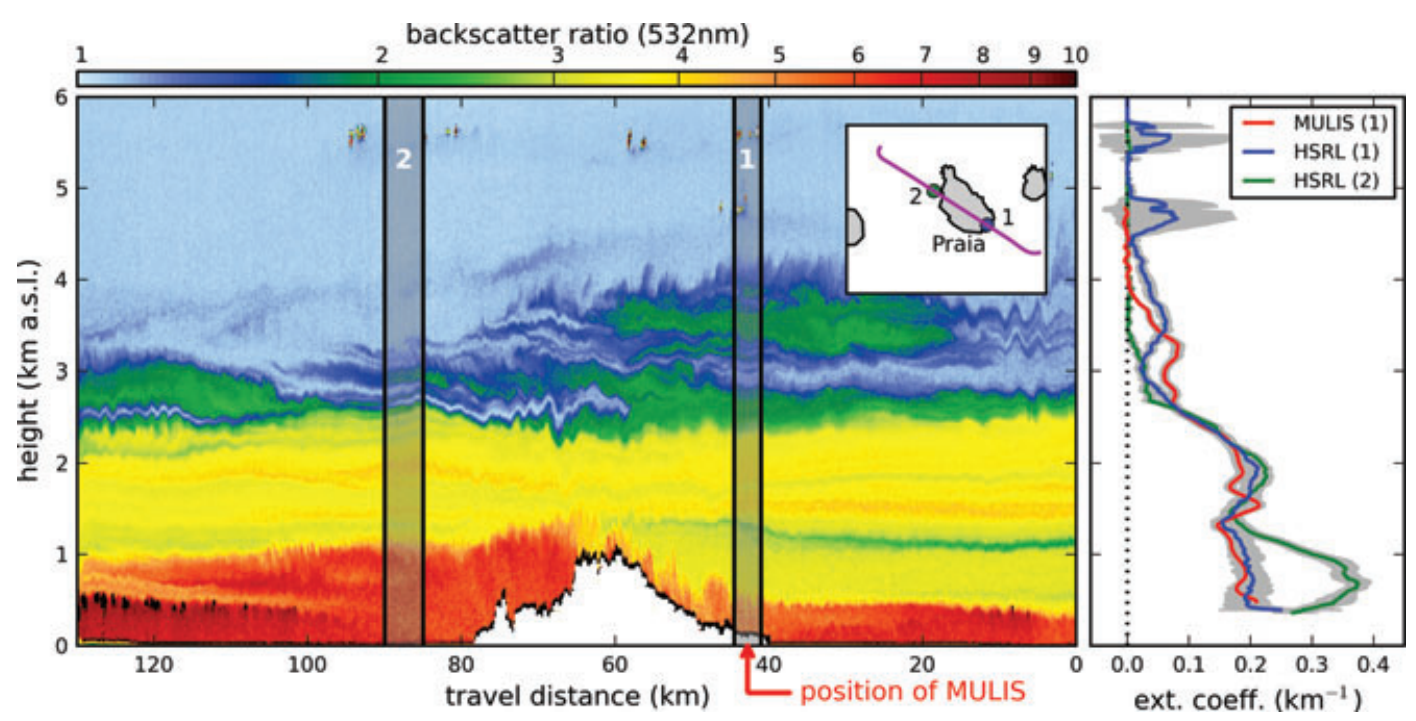

Fig. 11. Illustration of the island effects. The left plot shows the backscatter ratio at $532 \mathrm{~nm}$ measured by the HSRL during an overpass over the Santiago island on 25 January 2008 between 16:05 and 16:22 UTC. The inset shows the flight track during the sounding, the flight direction was from SE to NW. The shaded areas denoted with ' 1 ' and ' 2 ' are intervals used to derive average profiles of the extinction coefficient. Interval 1 is centred around Praia airport where the ground-based lidar system MULIS operated by the Meteorological Institute of the University of Munich (Groß et al., 2011a, b) was taking measurements at the same time. Interval 2 is located above the open sea just off the northwestern coast of the island. The right panel shows the vertical profiles of the mean extinction coefficient extracted from the HSRL data at those two locations (the grey area indicates the $3 \sigma$ statistical error on the average, the averaging times are $27.0 \mathrm{~s}$ for interval 1 and $32.2 \mathrm{~s}$ for interval 2). The red line represents the profile measured by MULIS (averaging time $2 \mathrm{~h}$ ). While the data from the different lidar systems are in reasonable agreement at the same location, the comparison of the profiles taken at the different locations shows that presence of the island has strong effect on the vertical structure of the different aerosol layers (see Engelmann et al., 2011; for a detailed study of the island effects). Therefore, the averaging intervals used to compare lidar data with in situ measurements have to be chosen carefully to ensure that the conditions are comparable.

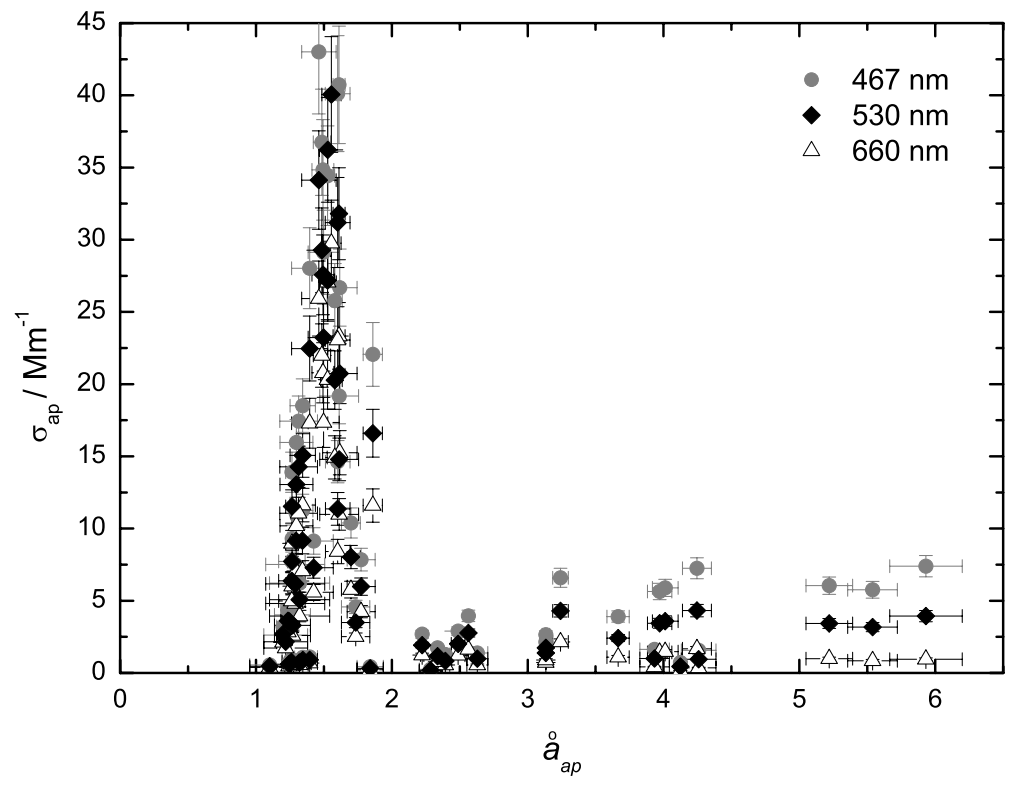

Fig. 12. Scatter plot showing the absorption coefficient $\sigma_{\text {ap }}$ as a function of the

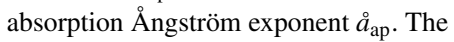
different symbols refer to the absorption coefficient measured at the different wavelengths. Mineral dust aerosol layers are only weakly absorbing and have values of $\stackrel{\circ}{a}_{\text {ap }}$ between 2.5 and 5.9. In contrast, biomass burning layers are strongly absorbing and show values of $\stackrel{\circ}{a p}_{\text {ap }}$ between 1.2 and 1.9. All values are given for STP conditions.

of transport (Petzold et al., 2007) is indicated in Fig. 15. Both, boreal and tropical biomass burning aerosol, show a strongly enhanced accumulation mode, which peaks between 200 and $300 \mathrm{~nm}$ in diameter. In both cases, particles larger than $1 \mu \mathrm{m}$ are present. However, the tropical biomass burning aerosol con- tains a significant amount of large $10-\mu \mathrm{m}$ particles which are not present in the boreal forest fire aerosol. As we will discuss in Section 4.3, these large particles are mineral dust particles originating from the region north of $11^{\circ} \mathrm{N}$ (see also Knippertz et al., 2011). 


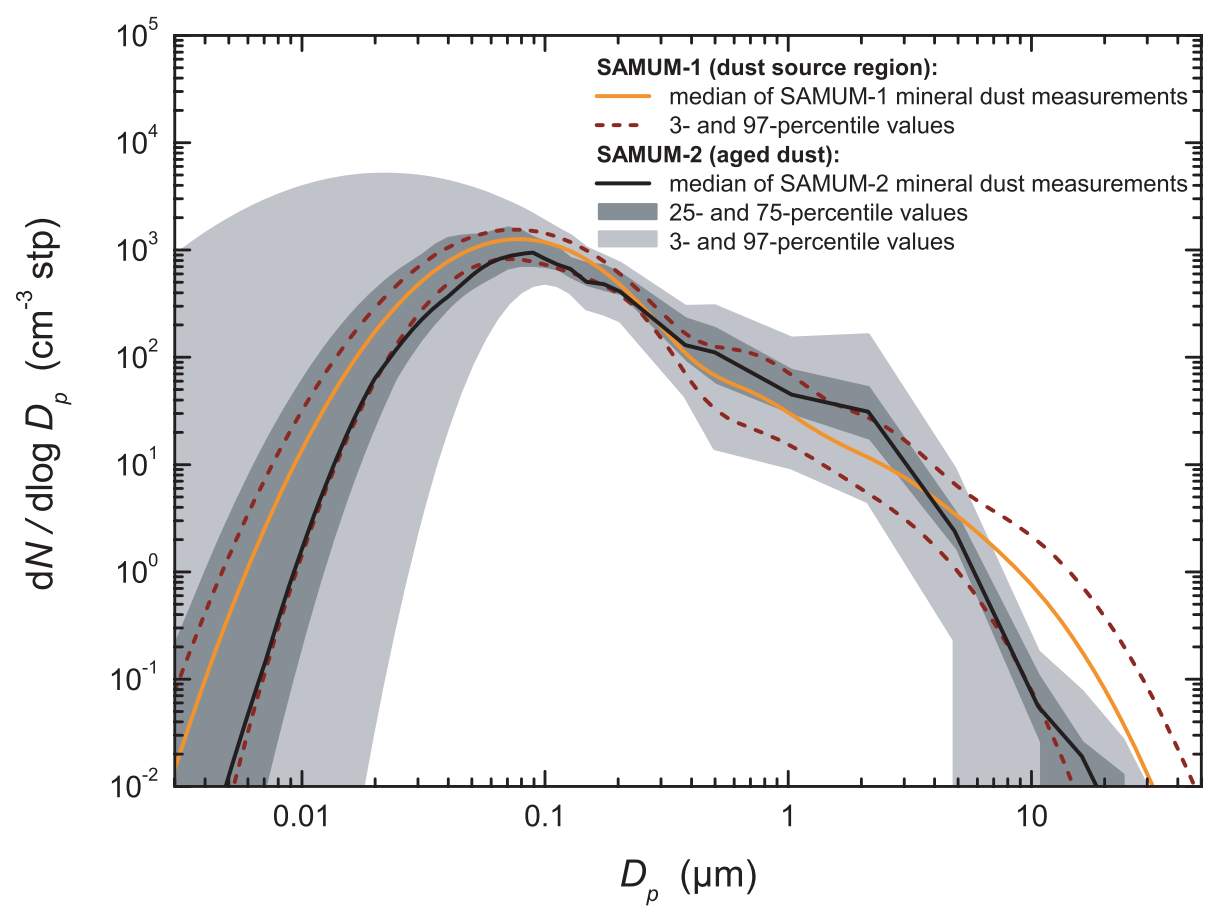

Fig. 13. Composite particle number size distribution of mineral dust aerosol measured during SAMUM-1 and SAMUM-2. The size distributions are derived from CPC, PCASP-100X, and FSSP-300 measurements. The orange and black line shows the median of the SAMUM-1 and SAMUM-2 measurements, respectively. The dark and light grey shaded areas indicate the 3rd, 25th, 75th and 97th percentile values for SAMUM-2. The brown dotted line denotes the 3rd and 97th percentile values of SAMUM-1. Mode parameters for these size distributions are given in Table 5. All numbers refer to STP conditions.

Table 5. Dust and biomass burning aerosol size distributions. The table lists the individual parameters for the median and 3rd, 25th, 75th and 97th percentile distributions

\begin{tabular}{|c|c|c|c|c|c|c|c|c|c|c|c|c|c|c|}
\hline & $\begin{array}{c}N_{1} \\
\left(\mathrm{~cm}^{-3}\right)\end{array}$ & $\begin{array}{c}C M D_{1} \\
(\mu \mathrm{m})\end{array}$ & $\begin{array}{l}G S D_{1} \\
(\mu \mathrm{m})\end{array}$ & $\begin{array}{c}N_{2} \\
\left(\mathrm{~cm}^{-3}\right)\end{array}$ & $\begin{array}{c}C M D_{2} \\
(\mu \mathrm{m})\end{array}$ & $\begin{array}{l}G S D_{2} \\
(\mu \mathrm{m})\end{array}$ & $\begin{array}{c}N_{3} \\
\left(\mathrm{~cm}^{-3}\right)\end{array}$ & $\begin{array}{c}C M D_{3} \\
(\mu \mathrm{m})\end{array}$ & $\begin{array}{l}G S D_{3} \\
(\mu \mathrm{m})\end{array}$ & $\begin{array}{c}N_{4} \\
\left(\mathrm{~cm}^{-3}\right)\end{array}$ & $\begin{array}{c}C M D_{4} \\
(\mu \mathrm{m})\end{array}$ & $\begin{array}{l}G S D_{4} \\
(\mu \mathrm{m})\end{array}$ & $\begin{array}{l}D_{\text {eff }} \\
(\mu \mathrm{m})\end{array}$ & $\begin{array}{c}T S P \\
\left(\mu \mathrm{g} \mathrm{m}^{-3}\right)\end{array}$ \\
\hline \multicolumn{15}{|c|}{ SAMUM-1, dust over the source region } \\
\hline Median & 940 & 0.08 & 1.98 & 17 & 0.60 & 1.55 & 9 & 1.40 & 1.90 & 1 & 4.50 & 1.85 & 6.27 & 913 \\
\hline$p_{03}$ & 480 & 0.07 & 1.72 & 115 & 0.18 & 1.47 & 17 & 0.50 & 1.95 & 2.1 & 1.95 & 1.82 & 2.67 & 131 \\
\hline$p_{25}$ & 790 & 0.08 & 1.90 & 13 & 0.60 & 1.55 & 7 & 1.40 & 1.90 & 0.7 & 4.50 & 1.75 & 5.16 & 535 \\
\hline$p_{75}$ & 980 & 0.08 & 2.08 & 20 & 0.60 & 1.55 & 11 & 1.40 & 1.90 & 1.3 & 4.58 & 1.87 & 6.88 & 1274 \\
\hline$p_{97}$ & 1220 & 0.08 & 2.06 & 43 & 0.66 & 1.52 & 13 & 1.80 & 1.60 & 2.7 & 4.95 & 1.92 & 9.23 & 3349 \\
\hline \multicolumn{15}{|c|}{ SAMUM-2, aged dust } \\
\hline Median & 550 & 0.08 & 1.82 & 80 & 0.35 & 1.82 & 18 & 1.45 & 1.66 & 0.09 & 4.50 & 1.88 & 2.56 & 330 \\
\hline$p_{03}$ & 200 & 0.10 & 1.44 & 40 & 0.22 & 1.40 & 6.5 & 0.62 & 1.82 & 1.7 & 1.48 & 1.62 & 1.53 & 33 \\
\hline$p_{25}$ & 380 & 0.08 & 1.69 & 65 & 0.22 & 1.47 & 26 & 0.54 & 1.92 & 6.5 & 1.48 & 1.76 & 2.17 & 152 \\
\hline$p_{75}$ & 1200 & 0.06 & 2.05 & 100 & 0.40 & 1.82 & 30 & 1.39 & 1.72 & 0.11 & 4.70 & 2.02 & 2.82 & 604 \\
\hline$p_{97}$ & 5800 & 0.02 & 2.90 & 130 & 0.45 & 1.82 & 68 & 1.54 & 1.64 & 0.29 & 4.74 & 2.00 & 3.00 & 1477 \\
\hline \multicolumn{15}{|c|}{ SAMUM-2, tropical biomass burning aerosol } \\
\hline Median & 280 & 0.12 & 1.16 & 800 & 0.22 & 1.31 & 15 & 0.52 & 1.51 & 4.2 & 1.60 & 1.69 & 1.04 & 104 \\
\hline$p_{03}$ & 20 & 0.13 & 1.10 & 40 & 0.22 & 1.30 & 0.5 & 0.64 & 1.55 & 0.08 & 1.55 & 1.69 & 0.61 & 3 \\
\hline$p_{25}$ & 100 & 0.12 & 1.16 & 210 & 0.22 & 1.31 & 2 & 0.55 & 1.48 & 2.7 & 1.15 & 1.68 & 0.88 & 24 \\
\hline$p_{75}$ & 750 & 0.13 & 1.30 & 1400 & 0.23 & 1.31 & 30 & 0.52 & 1.48 & 7.7 & 1.58 & 1.71 & 1.00 & 198 \\
\hline$p_{97}$ & 400 & 0.07 & 1.60 & 3800 & 0.20 & 1.42 & 60 & 0.52 & 1.48 & 14 & 1.60 & 1.71 & 0.99 & 381 \\
\hline
\end{tabular}


Table 6. Presence of large coarse mode particles during SAMUM-1 and SAMUM-2. The percentage given refers to the number of cases in which particles above of a certain size were present

\begin{tabular}{|c|c|c|c|c|c|}
\hline $\begin{array}{l}\text { Field } \\
\text { experiment }\end{array}$ & $\begin{array}{c}\text { Number of } \\
\text { cases }\end{array}$ & $\begin{array}{l}\text { Particles with } \\
D_{\mathrm{p}} \geq 10 \mu \mathrm{m} \\
\text { present }\end{array}$ & $\begin{array}{l}\text { Particles with } \\
D_{\mathrm{p}} \geq 20 \mu \mathrm{m} \\
\text { present }\end{array}$ & $\begin{array}{c}\text { Particles with } \\
D_{\mathrm{p}} \geq 30 \mu \mathrm{m} \\
\text { present }\end{array}$ & $\begin{array}{c}\text { Particles with } \\
D_{\mathrm{p}} \geq 40 \mu \mathrm{m} \\
\text { present }\end{array}$ \\
\hline SAMUM-1 (fresh dust, Morocco), 2006 & 49 & $100 \%$ & $90 \%$ & $51 \%$ & $20 \%$ \\
\hline SAMUM-2 (aged dust, Cape Verde), 2008 & 24 & $88 \%$ & $33 \%$ & $0 \%$ & $0 \%$ \\
\hline
\end{tabular}

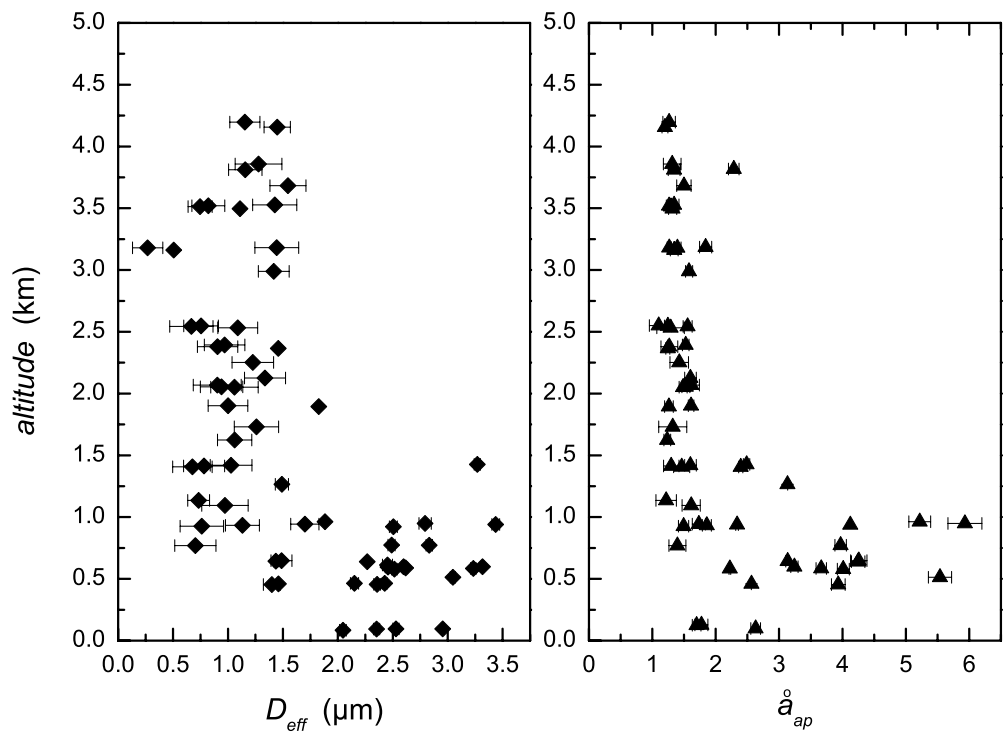

Fig. 14. Effective diameter $D_{\text {eff }}$ and

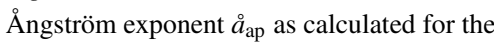
24 mineral dust, 31 biomass burning and 10 mixed (dust, anthropogenic pollution and marine aerosol) layers.

From the size distribution data, a median $D_{\text {eff }}$ of $1.06 \mu \mathrm{m}$ $\left(p_{03}=0.67 \mu \mathrm{m} ; p_{97}=1.83 \mu \mathrm{m}\right)$ was derived. This is higher than the $D_{\text {eff }}(0.2-0.72 \mu \mathrm{m})$ inferred from multiwavelength lidar measurements (Tesche et al., 2011a). However, for the inversion of the lidar data, only the fine mode fraction was considered, while the effective diameter calculated here refers to the size range between 0.01 and $30 \mu \mathrm{m}$. To make the data comparable, the fine mode effective diameter $D_{\text {eff,fine }}$ (size range $0.01-1 \mu \mathrm{m}$ ) was calculated from the in situ measurements (Table 3 ). We find a median $D_{\text {eff,fine }}$ of $0.33 \mu \mathrm{m}\left(p_{03}=0.28 \mu \mathrm{m} ; p_{97}=0.80 \mu \mathrm{m}\right)$ which is in very good agreement with the findings reported by Tesche et al. (2011a).

\section{Discussion}

\subsection{Testing closure between observed size distributions and optical properties}

Similar to SAMUM-1 (Weinzierl et al., 2009), we evaluated the quality of the measured size distributions by comparing extinction coefficients calculated from the in situ measurements and measured directly with the HSRL. For that purpose, the microphysical properties of the biomass burning and mineral dust aerosol described in the preceding sections (parametrized size distribution, refractive index and aerosol mixing state) entered an aerosol optical model (Fiebig et al., 2005), which allows the calculation of spectral aerosol optical properties like extinction coefficient or single-scattering albedo. The aerosol optical model is based on the Bohren and Huffman (1983) Mie code for the treatment of spherical particles and on the Ackerman and Toon (1981) Mie code for the treatment of coated spheres. The model includes a lookup table of common spectral refractive indices for various materials available in the literature. As input data of the aerosol optical model (besides size distribution and mixing state) the volume fraction of chemical components in the aerosol particles as derived from the $3 \lambda$-PSAP measurements are used (see also Section 2.4). The aerosol optical model is capable of treating internally and externally mixed aerosol modes and coated spheres within the same aerosol. Additionally, the model has a feature that allows the size-dependent specification of the chemical particle composition and the aerosol mixing state. All parameters can be specified for each mode separately. Following the results from the single particle analysis (Kandler et al., 


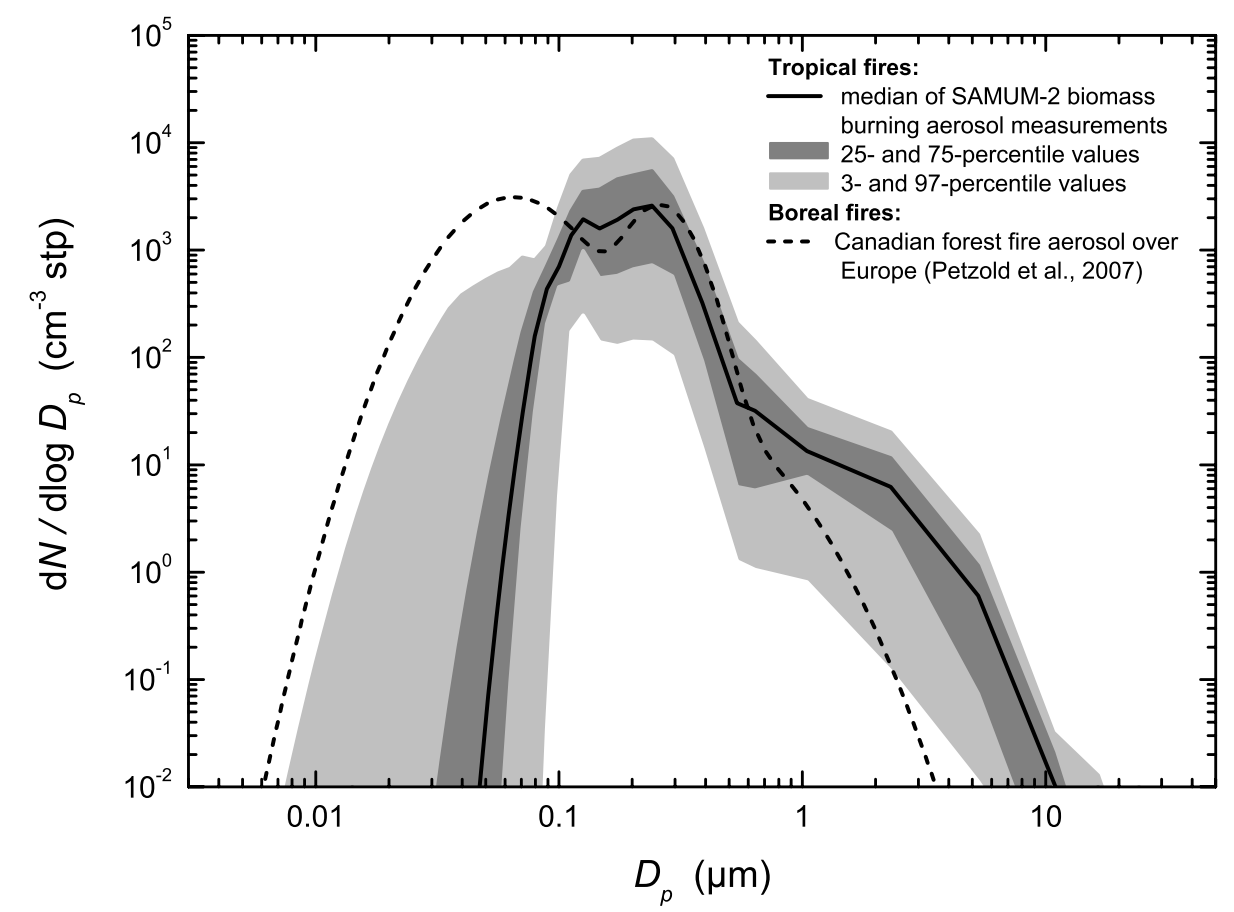

Fig. 15. Composite number size distributions of biomass burning aerosol measured during SAMUM-2. The size distributions are derived from CPC, PCASP-100X and FSSP-300 measurements. The dark and light grey shaded areas indicate the 3rd, 25th, 75th and 97th percentile values for SAMUM-2, while the black line shows the median of all tropical biomass burning layers. Mode parameters for these size distributions are given in Table 5. For comparison, a size distribution (dotted line) of boreal forest fire aerosol is added. All numbers refer to STP conditions.

2011; Lieke et al., 2011), we assumed that the effective chemical composition derived from the $3 \lambda$-PSAP measurements is appropriate for three modes of the parametrized size distribution. For particles in the coarse mode, we assumed that the particles were entirely composed of $\mathrm{SiO}_{2}$. We tested the impact of choosing an absorbing refractive index for three modes only for most cases and for all four modes for one case and found that the impact on the derived extinction coefficient was smaller than $1 \%$. A larger difference was found for the derived absorption (53\%) and scattering coefficients (16\%).

Figure 16 depicts four examples of vertical profiles of HSRL extinction measurements (black lines) and calculated extinction coefficients $\sigma_{\text {ep }}$ (red symbols) for the wavelength of $532 \mathrm{~nm}$. The calculated extinction coefficient, $\sigma_{\text {ep }}$ (in situ) reflects the vertical layering of the atmosphere. Figure 17 illustrates that the values calculated from the size distribution and the direct measurements of the extinction coefficient agree well within the error bars. The HSRL-in situ difference, computed as $\mid\left[\sigma_{\mathrm{ep}}(i n\right.$ situ $\left.)-\sigma_{\mathrm{ep}}(H S R L)\right] / \sigma_{\mathrm{ep}}(H S R L) \mid$, covers a range from $-33 \%$ to $+47 \%$. On average, the calculated extinction coefficients agree with the values measured with HSRL within $23 \%$. Although, the aerosol layers at a given location are not changing rapidly with time, we expect some variation between the time of the lidar and the in situ measurements. In addition, the position of the lidar and the in situ measurements did not always exactly coincide. Especially the presence of the islands can lead to a stronger horizontal variability in particular at low levels in the mineral dust layers (see Section 3.2 and Fig. 11).

\subsection{Source regions and age of the observed aerosols from trajectory calculations}

To determine the potential source regions and age of the observed aerosols, we computed backward trajectories starting from the location of in situ measurements using the trajectory analysis program FLYTUL version 0.3 (Hamburger, 2011). FLYTUL is based on the three-dimensional trajectory model LAGRANTO (Wernli and Davies, 1997; Wernli, 1997) and follows the path of an air parcel backwards using meteorological input data from ECMWF operational analyses and forecasts (Persson and Grazzini, 2007). To achieve a $3 \mathrm{~h}$ resolution the 00, 06, 12 and 18 UT analysis data set from ECMWF were complemented using the prognostic data at $03,09,15$ and 21 UT. The trajectories are computed with a temporal resolution of $3 \mathrm{~h}$ and reach back in time up to $168 \mathrm{~h}$. The spatial resolution of the ECMWF fields is $0.5^{\circ}$ by $0.5^{\circ}$ in 91 vertical levels. Here we focus on the cases of a mineral dust and a biomass burning aerosol layer observed during the transfer flight from the Canary Islands to Cape Verde on 19 January 2008 (flight ID 080119c, layers L04 and L05. Figures 18 and 19 show maps with ensembles of trajectories 

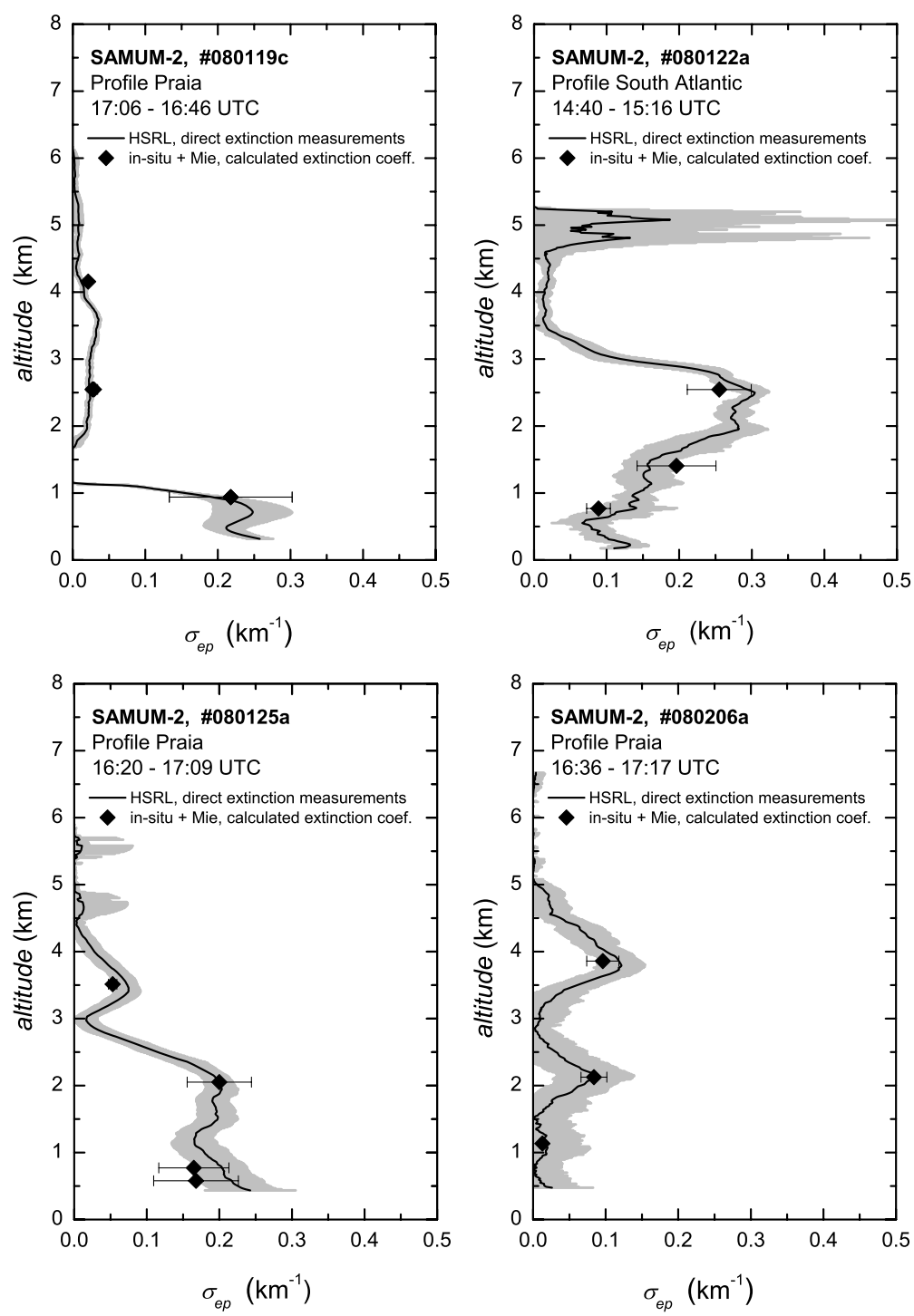

Fig. 16. Testing closure between observed size distributions and optical properties. Vertical profiles of lidar extinction measurements (black lines) and extinction coefficients $\sigma_{\text {ep }}$ are calculated from the in situ measurements on the basis of Mie theory (black diamonds). All panels show an intercomparison of HSRL extinction measurements at $532 \mathrm{~nm}$ and calculated extinction coefficients at $532 \mathrm{~nm}$ for 19, 22, 25 January 2008 and 6 February 2008, respectively. The grey-shaded areas indicate the standard deviation of the extinction coefficient within the lidar averaging time. The times given in the plot indicate the time of the in situ measurements. Lidar averaging times can be taken from Table A2.

initiated randomly inside a $1 \mathrm{~km} \times 1 \mathrm{~km} \times 200 \mathrm{~m}$ box around the location of the measurement sites. The numbers along the trajectories indicate the time in hours for the median trajectory of the ensemble. The pressure altitude of the trajectory is colour-coded in the map and also shown as a function of time in the lower panel of each figure. The air masses represented by the trajectory are assumed to obtain their aerosol loading when the trajectory passes over regions with significant dust activation and/or wild fire activity at an altitude close to the boundary layer. The shaded regions in the maps in Figs. 18 and 19 correspond to the areas of strong dust emission (yellow) and biomass burning activity (red) identified in Heinold et al. (2011).

The trajectories for 080119 c L04 shown in Fig. 18 pass primarily over the southern part of West-Africa, a region with strong wild-fire activity. This agrees well with the classification based on HSRL data and the measured Ångström exponents that the aerosol in this layer was dominated by biomass burning aerosol (Section 2.5). Knippertz et al. (2011) show that the emission of biomass burning aerosol in this region reaches to altitudes of up to $10 \mathrm{~km}$, well above the levels of the trajectories shown in Fig. 18. From this analysis the minimum age of the observed aerosol can be estimated to be around $4 \mathrm{~d}$.

Based on the HSRL-in situ aerosol classification described in Section 2.5, the aerosol in 080119c L05 was found to be primarily mineral dust, again in agreement with the trajectories shown in Fig. 19 which pass through the more central Saharan desert area in Mali and Algeria before reaching the northern Senegalese coast. Here the trajectory ensemble stays relatively tight. Although the trajectories do not directly cross the centre of strong dust activation areas, they at least pass the edges of those dust activation areas. Therefore, it is conceivable that the particles found at L05 are dominated by mineral dust. In this 


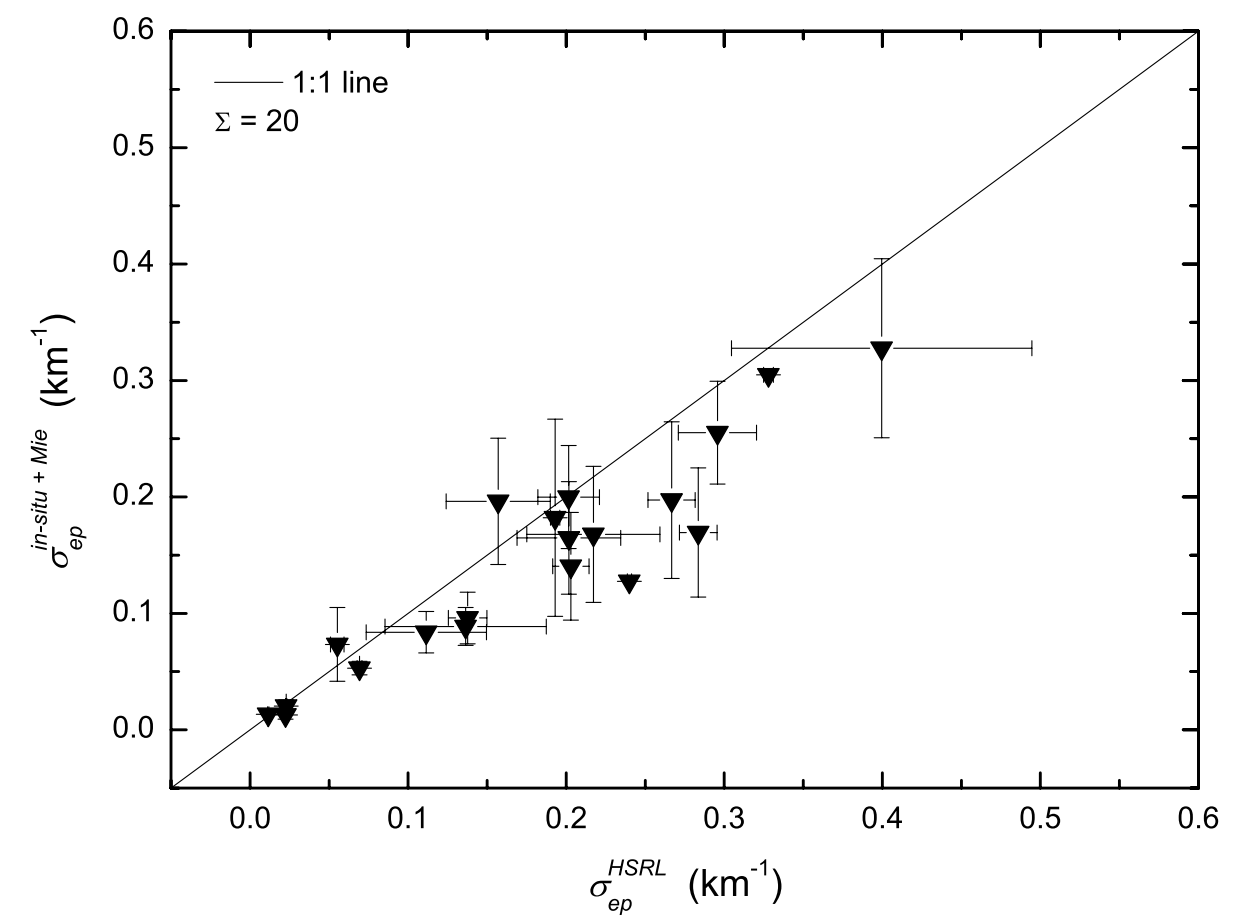

Fig. 17. Closure of extinction coefficient calculated from in situ measurements with Mie theory and measured with the HSRL (532 nm). The extinction coefficients derived from the different methods agree within the error bars.

case it is more difficult to narrow down the age of the aerosol. The minimum age has to be around $24 \mathrm{~h}$, the time when the trajectories cross the African coastline. The most likely age is between 2 and $4 \mathrm{~d}$.

\subsection{The presence of large dust particles in the biomass burning layers}

The mean vertical profiles measured during SAMUM-2 as well as the particle size distributions measured at the individual constant altitude sequences showed that the biomass burning layers always contained a small fraction of coarse mode particles which are not expected in pure biomass burning layers. Multiwavelength and polarization lidar measurements can be used to investigate the contributions of different types of aerosols in individual aerosol layers and allow the separation of different aerosol types (see Section 2.5 and Tesche et al., 2009, 2011a). The depolarization ratios measured in the biomass burning layers already indicated that the biomass burning layers are mixtures of dust and biomass burning aerosol rather than pure biomass burning layers. To investigate this observation in more detail, the contribution of mineral dust to the optical properties of the biomass burning layers was computed on the basis of the HSRL measurements at locations at or close to the in situ sampling sites. The determination of the dust fraction follows the method to separate mineral dust and smoke aerosol discussed in Tesche et al. (2009); the results are shown in Fig. 20. The computation requires the assumption of particle linear depolarization ratios for pure mineral dust and non-dust aerosol which are taken from the measurements with ground-based lidar systems during the SAMUM-1 campaign in Tesche et al. (2009). This assumption may lead to a systematic offset of the derived dust fractions, which can explain that the dust fraction values are less than $100 \%$ even for pure dust layers. Relative to each other the computed dust fractions are, however, comparable.

Figure 20 shows that all biomass burning aerosol layers contain a varying fraction of large dust particles. It is conceivable that these large particles are already mixed into the biomass burning layers at the location of the biomass emissions. In fact, we have not seen the mixing of a pure biomass burning plume and a pure mineral dust layer. To investigate the source of the dust particles further, we calculated backward trajectories for all biomass burning cases. Figure 21 shows the trajectories for L03 of flight 080206a. The aerosol measured in this layer is dominated by biomass burning aerosol, however, also contains a large number of dust particles (dust fraction: $49 \%, D_{\text {eff }}=$ $1.42 \mu \mathrm{m}$ ). The trajectories to this site most recently passed over active biomass burning regions as expected. Following them further back in time it is apparent that a substantial number of the trajectories have passed over areas with strong dust emissions further north within 1-3 d before entering the fire regions. These findings are in agreement with Knippertz et al. (2011) who showed that mineral dust is transported into the fire regions from areas north of $11^{\circ} \mathrm{N}$. 


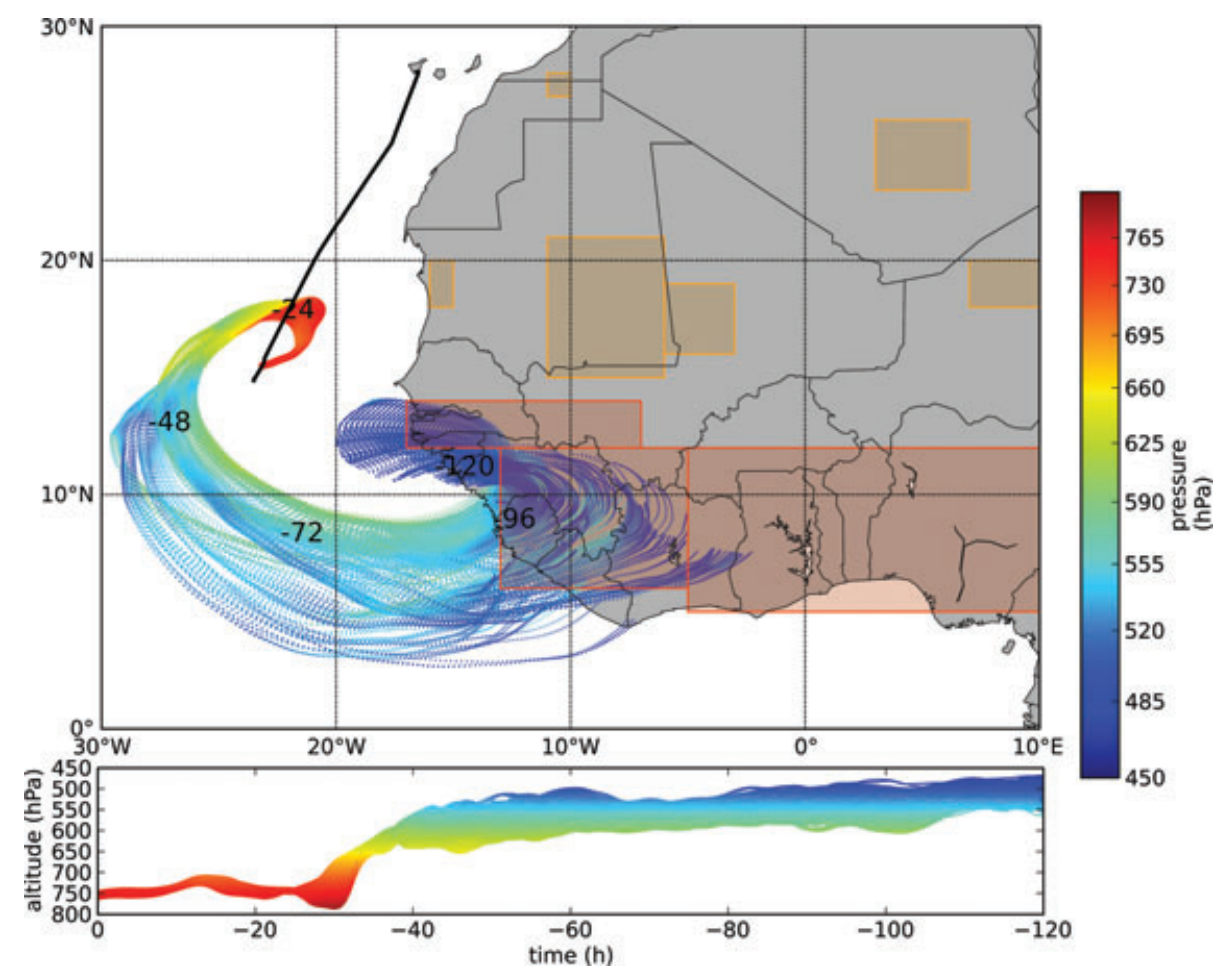

Fig. 18. Trajectories computed for the locations of the in situ measurement at layer L04 during the transfer flight from the Canary Islands to Cape Verde on 19 January 2008 (flight $080119 \mathrm{c}$ ). The map shows ensembles of trajectories computed backwards in time starting from the location where aerosol in situ measurements were taken. The colour-coding of the trajectories indicates the pressure altitude of the trajectories. The numbers refer to the approximate travel time of air parcels on the mean trajectory to the measurement site in hours, which gives an indication of the minimum age of the sampled aerosol. The regions shaded in orange indicate areas where Heinold et al. (2011) find strong dust emissions during this time period; red shaded areas correspond to regions with significant fire activity. The lower panel shows the pressure altitude as a function of time for the entire bundle of trajectories. The analysis shows that the air sampled at layer L04 predominantly passed over areas with strong fire activity in the Sahel and coastal region of West Africa.

\subsection{Aging of mineral dust}

The comparison of mineral dust measured during SAMUM-1 close to the source region and during SAMUM-2 in the longrange transport regime along and west of the coast of Western Africa shows similarities and differences (Fig. 13). Most of the mineral dust size distributions measured during SAMUM-2 are within the envelope of the SAMUM-1 measurements. However, in the coarse mode size range, the number of super-micron particles is clearly depleted and the particle number concentrations measured are observed to be at the lower end of number concentrations measured during SAMUM-1. Figure 22 depicts vertical profiles of maximum particle diameters ${ }^{4} D_{\mathrm{p}, \max }$ measured during SAMUM-1 (grey triangles) and SAMUM-2 (black diamonds). During both field experiments no altitude dependency of the maximum particle size measured is visible. However, maximum particle sizes detected during SAMUM-1 are larger

${ }^{4}$ Following Weinzierl et al. (2009), we define the maximum particle size as the size of the particles that occur at a concentration of $10^{-2} \mathrm{~cm}^{-3}$. than those measured during SAMUM-2. The reason for the depletion of large coarse mode particles is gravitational settling during transport. While during SAMUM-1 particles with diameters larger than $10 \mu \mathrm{m}$ were always present, during SAMUM-2 $12 \%$ of the cases do not show particles of $10-\mu \mathrm{m}$ size (see Table 6). Furthermore, particles of $40 \mu \mathrm{m}$ diameter were present in about $20 \%$ of the SAMUM-1 measurements (2009), no particles with diameters larger than $30 \mu \mathrm{m}$ were found during SAMUM-2.

A further aging effect is observed in the accumulation mode: the mean accumulation mode diameter of the SAMUM-2 size distributions seems to be shifted to larger particle sizes and the accumulation mode number concentration is enhanced compared to SAMUM-1. This behaviour can be explained by particle microphysics: in general, the aging of an aerosol up to $1-2 \mathrm{~d}$ is dominated by condensational growth, followed by coagulational growth. Coagulation then changes the shape of the size distribution and shifts the mean particle diameter of the accumulation mode towards larger particle diameters, as we observed. 


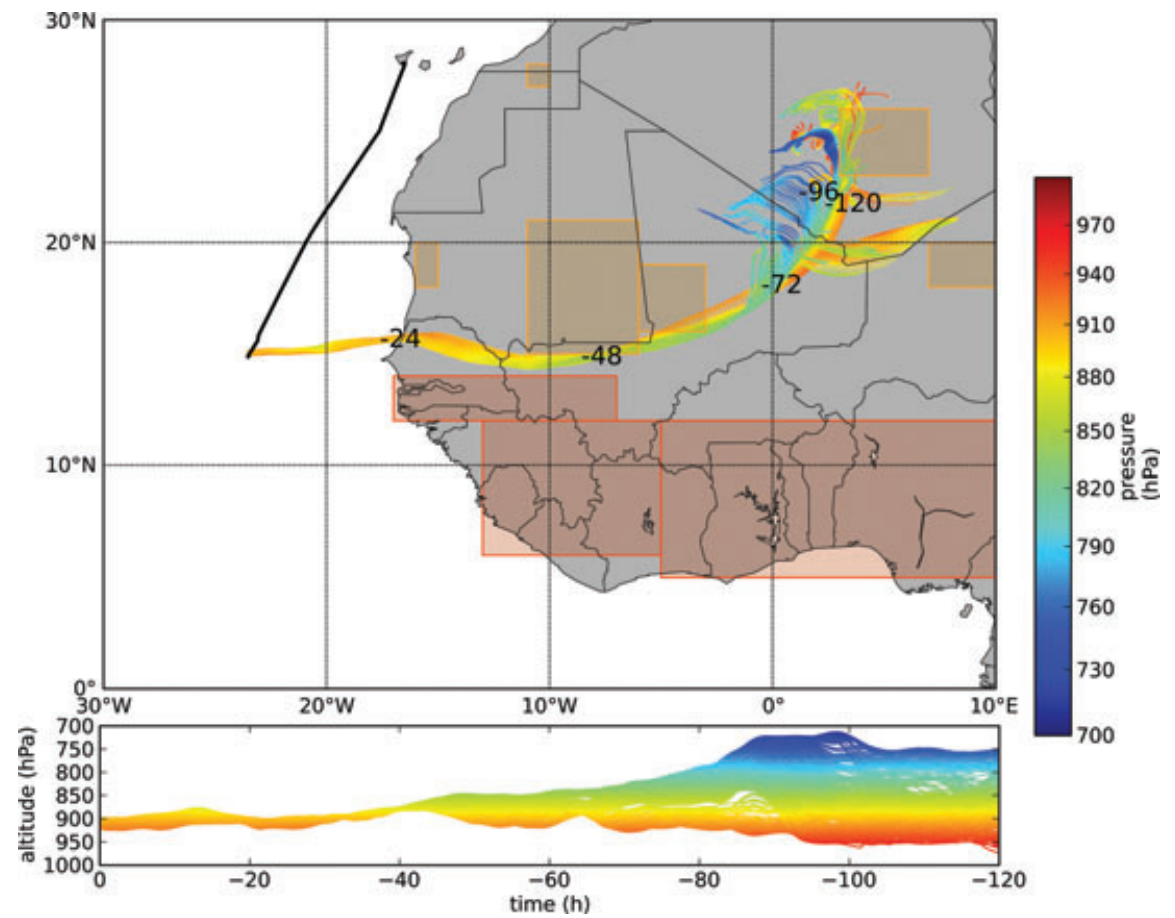

Fig. 19. Same as Fig. 18 but for L05 of flight 080119c. In this case the trajectories are found to pass primarily through dust-emitting regions.

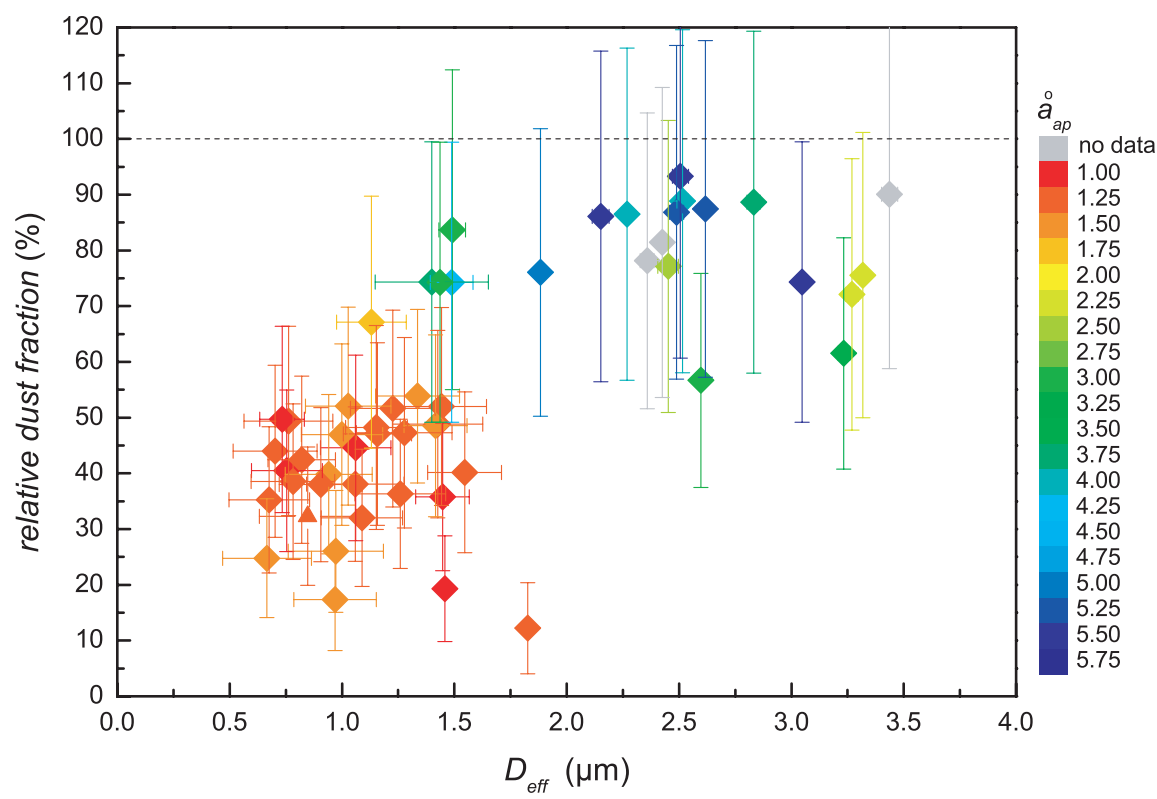

Fig. 20. The effective diameter $D_{\text {eff }}$ as a function of dust fraction for dust and biomass burning aerosol layers. The dust fraction was computed from HSRL measurements at or close to the locations of in situ aerosol sampling based on the method described by Tesche et al. (2009). See text.

\subsection{Contribution of elevated aerosol layers to the total $A O D$ in the atmospheric column between 0 and $10 \mathrm{~km}$}

Although the vertical depth biomass burning layers tended to be larger $(2.0 \pm 1.1 \mathrm{~km})$ than the vertical depth of the mineral dust plumes $(1.3 \pm 0.4 \mathrm{~km})$, the median AOD of the dust layers
(0.23) was more than a factor of two larger than AOD of the biomass burning layers (0.09). To investigate the impact of the elevated aerosol layers on the atmosphere, the contribution of the individual aerosol layers to the total AOD was calculated from the lidar data for the vertical profiles. We find that the dust layers constitute a median contribution of $75 \%\left(p_{03}=52 \%\right.$; 


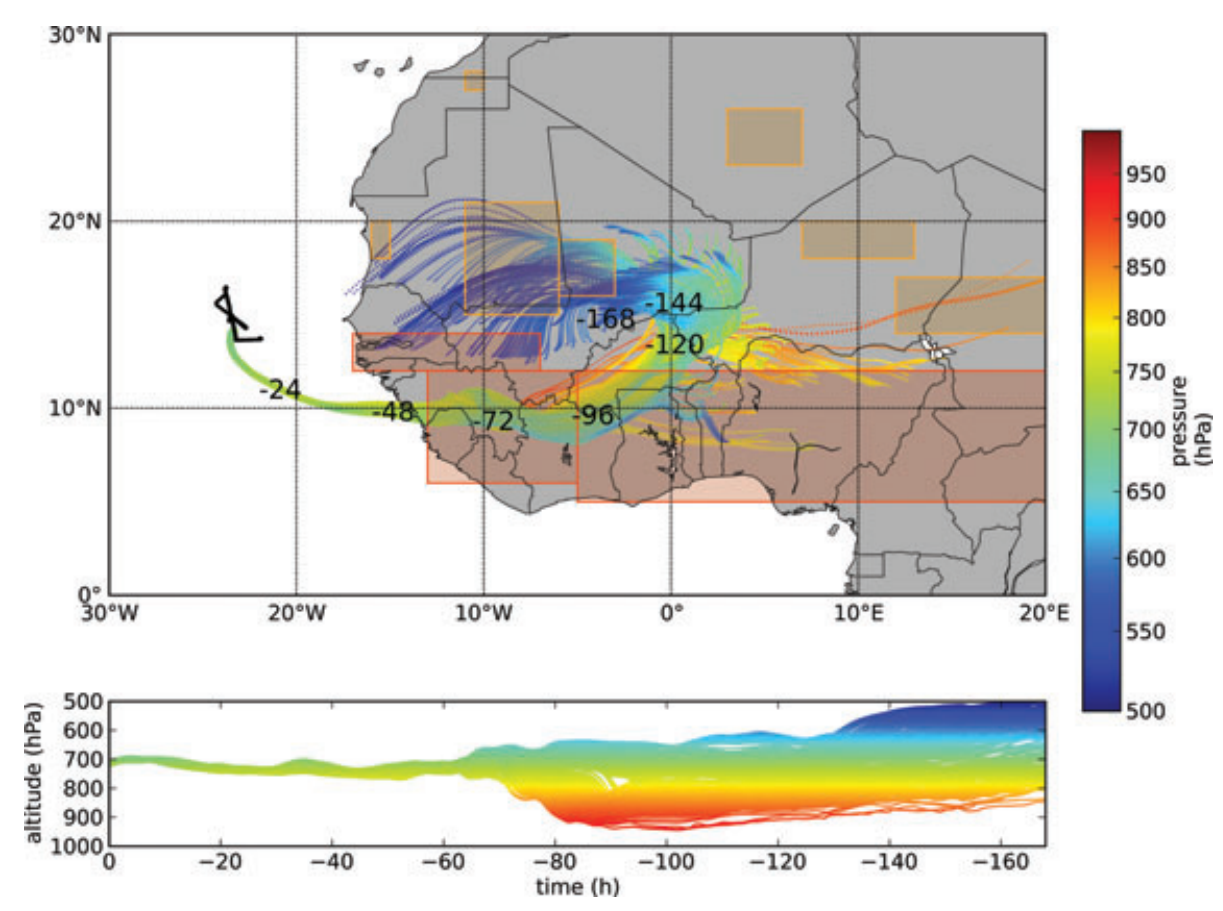

Fig. 21. Same as Fig. 18 but for L03 of flight 080206a where the air masses have passed through areas with emission of dust and tropical biomass burning aerosol.

$\left.p_{97}=85 \%\right)$ to the total AOD in the atmospheric column between 0 and $10 \mathrm{~km}$ altitude. On $3 \mathrm{~d}$ (28, 29 and 30 January), the mineral dust layers contributed as much as $80-88 \%$ to the AOD in the total atmospheric column. For the biomass burning layers, we find an median contribution of $37 \%\left(p_{03}=6 \% ; p_{97}=50 \%\right)$ to the AOD in the total atmospheric column. On $2 \mathrm{~d}$ (23 January and 6 February), the contribution of the biomass burning layers to the total AOD was even larger than $90 \%$. In those cases, the geometrical depth of the biomass burning plumes was between 3.3 and $4.6 \mathrm{~km}$. Given this large contribution to the total AOD, the elevated aerosol layers may have an important impact on atmosphere and climate, which should be evaluated in further studies.

\section{Summary and conclusion}

In our study, we have presented airborne observations of microphysical and optical properties of dust and tropical biomass burning aerosol layers in the Cape Verde region during SAMUM 2008. We classified the aerosol layers on the basis of HSRL and in situ measurements and investigated 65 biomass burning and mineral dust layers in detail. The mineral dust layers were-if present-below $2 \mathrm{~km}$ a.s.1., while the African biomass burning layers covered the altitude range between 2 and $5 \mathrm{~km}$. The geometrical depth of the individual aerosol layers was determined. We found an average depth of $1.3 \pm 0.4$ and $2.0 \pm 1.1 \mathrm{~km}$ for the mineral dust and biomass burning layers, respectively. For all layers the size distribution was calculated from a combina- tion of different particle sizing instruments and the absorption coefficient was inferred from a particle absorption photmeter.

The key findings of our study are the following:

As already shown in earlier studies, the absorption Ångström

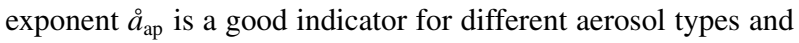
source regions. For mineral dust layers, we found a median value of $\stackrel{\circ}{a}$ ap $_{\text {of } 3.95}$. In the biomass burning layers, we derived 1.34 for $\stackrel{\circ}{a p}_{\text {ap }}$.

We observed different values of $D_{\text {eff }}$ for mineral dust and biomass burning layers. Typical values of $D_{\text {eff }}$ ranged between 1.4 and $3.4 \mu \mathrm{m}$ in mineral dust layers, and between 0.7 and 1.8 in biomass burning layers. Note that the effective diameter was derived for the size range between 0.01 and $30 \mu \mathrm{m}$. If only the diameter range between 0.01 and $1 \mu \mathrm{m}$ is considered, the effective diameter is reduced to $0.43-0.82 \mu \mathrm{m}$ for mineral dust and to $0.28-0.8 \mu \mathrm{m}$ for biomass burning aerosol. Within the individual biomass burning or mineral dust layers, no dependency of the $D_{\text {eff }}$ on the altitude of the measurements was observed.

We have shown that the tropical biomass burning layers always contained a certain amount of large mineral dust particles. Backward trajectory calculations revealed that for a substantial number of trajectories the air masses have passed over areas with strong dust emissions further north (north of $11^{\circ} \mathrm{N}$ ) within $1-3 \mathrm{~d}$ before entering the fire regions. Therefore, it is conceivable that these large particles are already present in the biomass burning layers at the location of the fires.

To evaluate the quality of the measured size distribution, we tested closure between observed size distributions and optical 


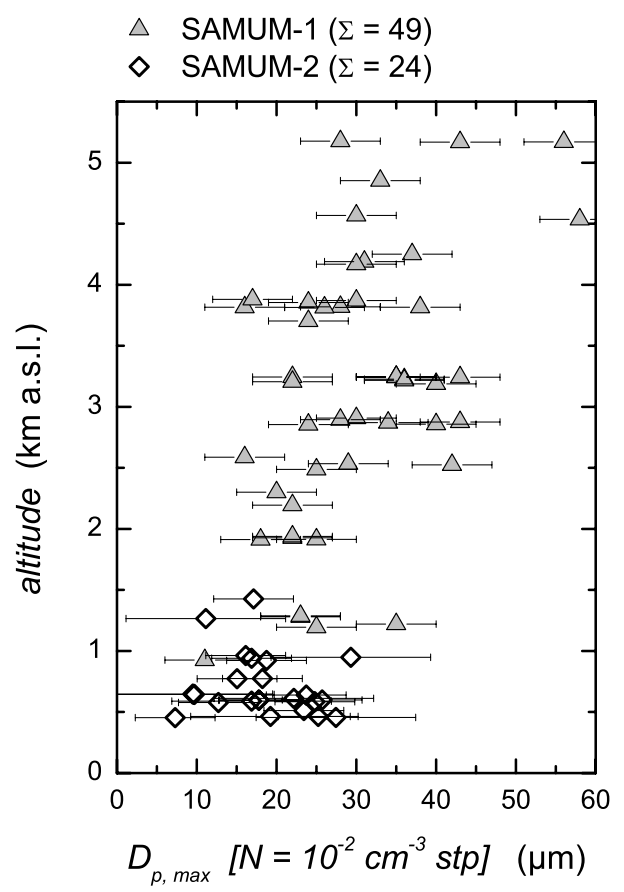

Fig. 22. Vertical distribution of the largest particles detected in each of the fresh 49 dust layers investigated during SAMUM-1 and in each of the aged 24 dust layers investigated during SAMUM-2. For aged dust, the diameter of the largest particle observed decreases compared to the fresh dust.

properties by comparing extinction coefficients calculated from the in situ measurements and measured directly with the HSRL. Calculated extinction coefficients reproduced very well the vertical layering and the structure of the directly measured extinction profile within the error bars of both methods. On average, calculated and directly measured extinction coefficients agreed within $23 \%$.

We compared mineral dust size distributions measured in the source region of the dust during SAMUM-1 with the properties found during SAMUM-2 in the long-range transport regime of the dust. We clearly see indications for dust aging. The number concentration of large coarse mode particles is depleted in the Cape Verde region compared to the values observed close to the dust source. Gravitational settling causes large coarse mode particles to disappear during transport. While during SAMUM-1 particles with diameters larger than $10 \mu \mathrm{m}$ were always present, in $12 \%$ of the SAMUM- 2 cases no particles of $10 \mu \mathrm{m}$ size are observed. In contrast to SAMUM-1, no particles of $40 \mu \mathrm{m}$ or larger were found during SAMUM-2.

The contribution of the individual aerosol layers to the total AOD was computed for 25 vertical profiles. The dust and biomass burning layers had a median AOD of 0.23 and 0.09 , respectively. We found that the median contribution of dust and biomass burning layers to the AOD of the total atmospheric column between 0 and $10 \mathrm{~km}$ are $75 \%$ and $37 \%$, respectively. On 5 of 10 flight days we found vertical profiles in which the contribution of the mineral dust and biomass burning layers to the total AOD was even larger than $90 \%$. Given this large contribution, such elevated aerosol layers may have important effects on atmosphere and climate, which should be investigated and evaluated in further studies.

\section{Acknowledgments}

This work was funded by the Deutsche Forschungsgemeinschaft (DFG) under grant number FOR 539 (Forschergruppe SAMUM), and by the Helmholtz Association under grant number VH-NG-606 (Helmholtz-HochschulNachwuchsforschergruppe AerCARE). We thank Hans Rüba, Andreas Minikin, Katharina Rasp, Peter Mahnke, Andreas Fix, Christoph Kiemle, Gerhard Ehret, and Reinhold Busen (all from DLR) for their assistance before and during the SAMUM field experiment. We are grateful to Hermann Mannstein (DLR) for providing the MSG satellite images, and we thank Andreas Dörnbrack and Andreas Schäfler (both from DLR) for preparing the weather forecasts, which we used during the campaign. The authors thank the European Centre for Medium-Range Weather Forecasts (ECMWF) for providing the meteorological fields in the framework of the special project 'Support Tool for HALO missions'. We thank Thomas Hamburger (DLR) for providing us with his FLYTUL software to analyze the backward trajectories, and we are grateful to the DLR Flight Operations for their excellent support during the preparation of the field study and during the research flights. Furthermore, the extensive support of the flight activities out of Praia Airport by the Cape Verde authorities, and in particular by Praia airport operations, air traffic control, TACV and the national meteorological service INMG are gratefully acknowledged. Without their outstanding contributions this work would not have been possible. 


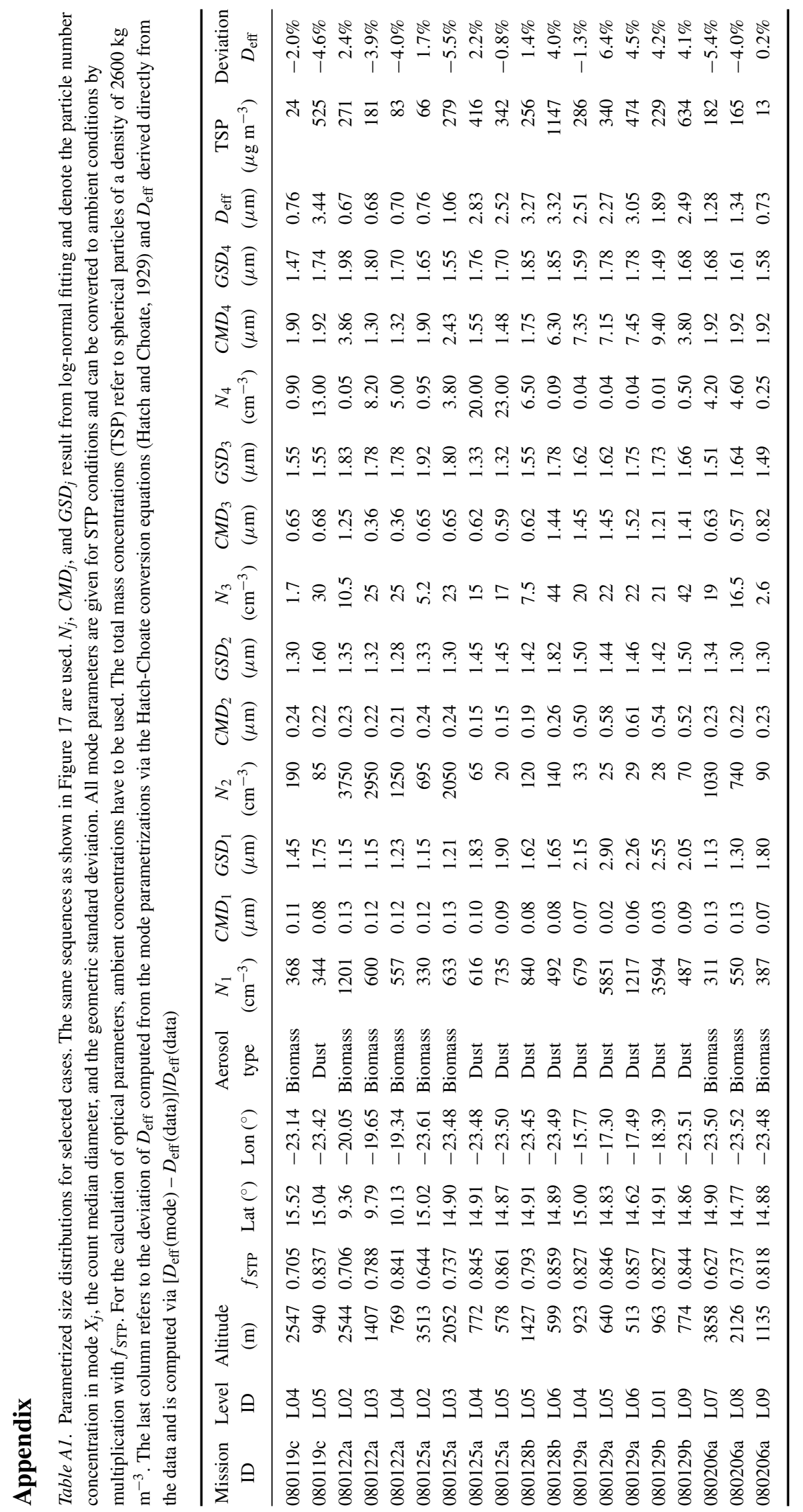




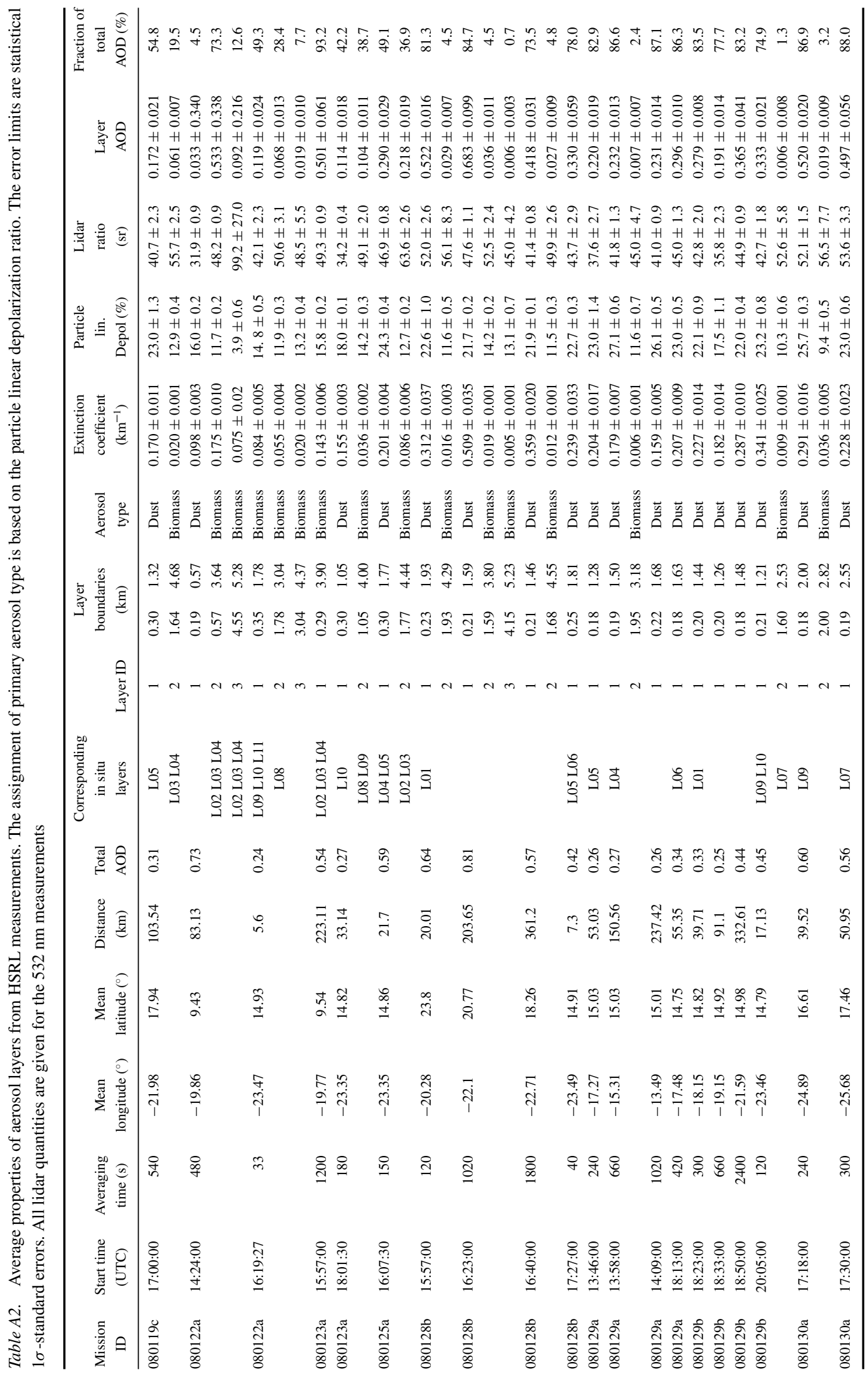




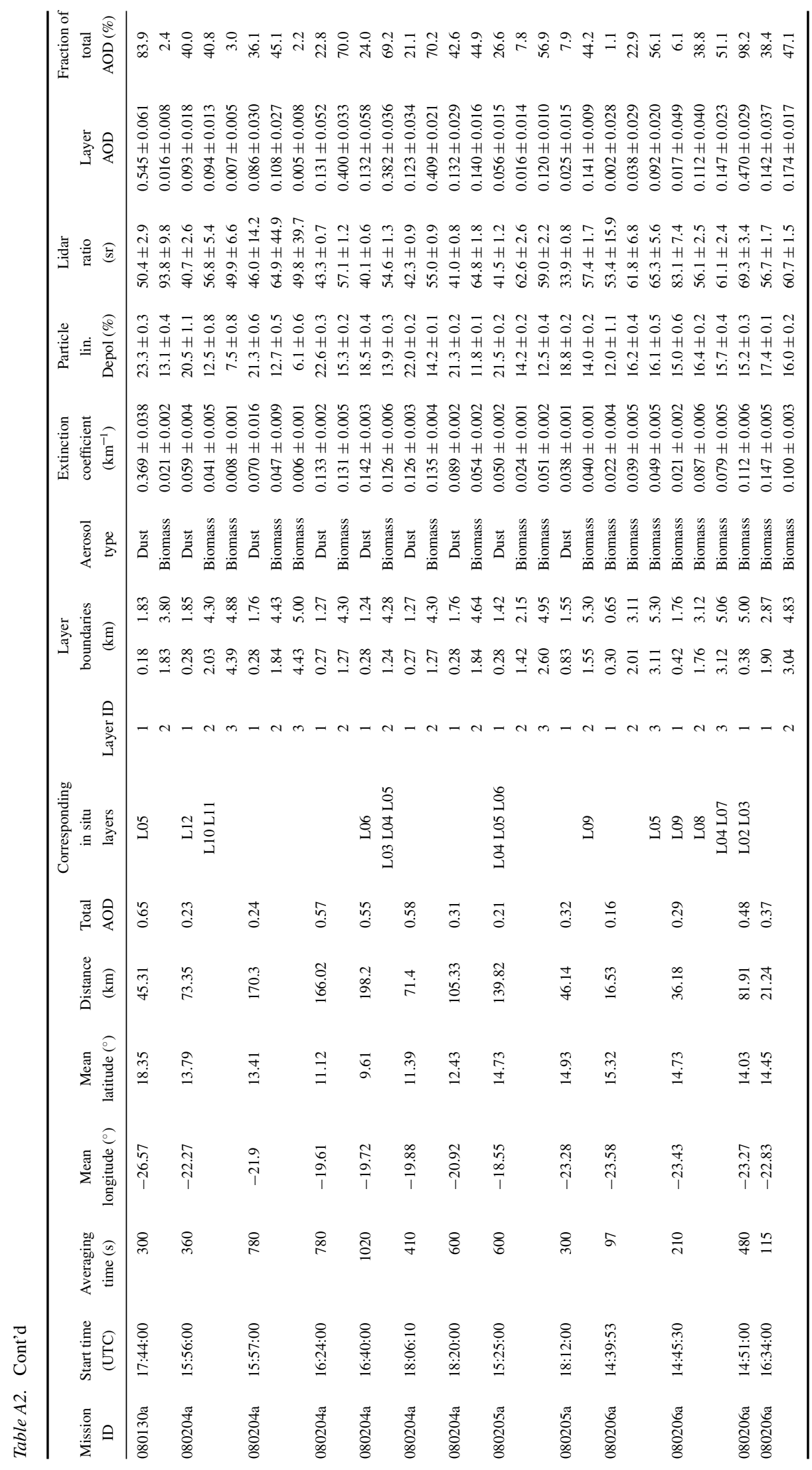




\section{References}

Ackerman, T. P. and Toon, O. B. 1981. Absorption of visible radiation in atmosphere containing mixtures of absorbing and nonabsorbing particles. Appl. Opt. 20, 3661-3668.

Ansmann, A., Mattis, I., Müller, D., Wandinger, U., Radlach, M. and co-authors. 2005. Ice formation in Saharan dust over central Europe observed with temperature/humidity/aerosol Raman lidar. J. Geophys. Res. 110, 1-12.

Ansmann, A., Petzold, A., Kandler, K., Tegen, I., Wendisch, M. and coauthors. 2011. Saharan Mineral Dust Experiments SAMUM-1 and SAMUM-2: what have we learned? Tellus 63B, this issue.

Bauer, S., Bierwirth, E., Esselborn, M., Heinold, B., Macke, A. and co-authors. 2011. Airborne spectral radiation measurements to derive single scattering albedo and solar radiative forcing of Saharan dust mixed with biomass burning smoke particles. Tellus 63B, this issue.

Bohren, C. F. and Huffman, D. R. 1983. Absorption and Scattering of Light by Small Particles. New York, John Wiley \& Sons, Inc, 544.

Bond, T. C., Anderson, T. L. and Campbell, D. 1999. Calibration and intercomparison of filter-based measurements of visible light absorption by aerosols. Aerosol Sci. Technol. 30, 582-600.

Clarke, A. D. 1991. A thermo-optic technique for in situ analysis of size-resolved aerosol physicochemistry. Atmos. Environ., Part A 25, 635-644.

Engelmann, R., Ansmann, A., Fruntke, J., Seifert, P., Tesche, M. and co-authors. 2011. Doppler lidar observations of heat-island effects on vertical mixing of dust and smoke over Cape Verde during SAMUM2. Tellus 63B, this issue.

Esselborn, M., Wirth, M., Fix, A., Tesche, M. and Ehret, G. 2008. Airborne high spectral resolution lidar for measuring aerosol extinction and backscatter coefficients. Appl. Opt. 47, 346-358.

Esselborn, M., Wirth, M., Fix, A., Weinzierl, B., Rasp, K. and co-authors. 2009. Spatial distribution and optical properties of Saharan dust observed by airborne high spectral resolution lidar during SAMUM 2006. Tellus 61B, 131-143.

Fiebig, M. 2001. Das troposphärische Aerosol in mittleren BreitenMikrophysik, Optik und Klimaantrieb am Beispiel der Feldstudie LACE 98. Ph.D. Thesis. Ludwig-Maximilians-Universität, München

Fiebig, M., Petzold, A., Wandinger, U., Wendisch, M., Kiemle, C. and co-authors. 2002. Optical closure for an aerosol column: Method, accuracy, and inferable properties applied to a biomass-burning aerosol and its radiative forcing. J. Geophys. Res. 107, 8130.

Fiebig, M., Stein, C., Schröder, F., Feldpausch, P. and Petzold, A. 2005. Inversion of data containing information on the aerosol particle size distribution using multiple instruments. J. Aerosol Sci. 36, 1353-1372.

Freudenthaler, V., Esselborn, M., Wiegner, M., Heese, B., Tesche, M. and co-authors. 2009. Depolarization ratio profiling at several wavelengths in pure Saharan dust during SAMUM 2006. Tellus 61B, 165-179.

Groß, S., Gasteiger, J., Freudenthaler, V., Wiegner, M., Geiß, A. and co-authors. 2011a. Characterization of the planetary boundary layer during SAMUM-2 by means of lidar measurements. Tellus $63 \mathrm{~B}$, this issue.

Groß, S., Tesche, M., Freudenthaler, V., Toledano, C., Wiegner, M. and co-authors. 2011b. Characterization of Saharan dust, marine aerosols and mixtures of biomass burning aerosols and dust by means of multi-wavelength depolarization- and Raman measurements during SAMUM-2. Tellus 63B, this issue.
Hamburger, T. 2011. Aerosol microphysical properties during anticyclonic flow conditions over Europe. Ph.D. Thesis. LudwigMaximilians-Universität, München.

Hansen, J. E. 1971. Multiple scattering of polarized light in planetary atmospheres. Part II. Sunlight reflected by terrestrial water clouds. $J$. Atmos. Sci. 28, 1400-1426.

Hansen, J. E. and Travis, L. D. 1974. Light-scattering in planetary atmospheres. Space Sci. Rev. 16, 527-610.

Hatch, T. and Choate, S. P. 1929. Statistical description of the size properties of non uniform particulate substances. J. Franklin Institute 207, 369-387.

Haywood, J. M., Allan, R. P., Culverwell, I., Slingo, T., Milton, S. and co-authors. 2005. Can desert dust explain the outgoing longwave radiation anomaly over the Sahara during July 2003 ? J. Geophys. Res. 110, $1-14$.

Heinold, B., Tegen, I., Schepanski, K., Tesche, M., Esselborn, M. and co-authors. 2011. Regional modelling of Saharan dust and biomass burning smoke - Part 1: Model description and evaluation. Tellus 63B, this issue.

Kandler, K., Lieke, K., Benker, N., Emmel, C., Küpper, M. and coauthors. 2011. Electron microscopy of particles collected at Praia, Cape Verde, during the Saharan Mineral dust experiment: particle chemistry, shape, mixing state and complex refractive index. Tellus 63B, this issue.

Knippertz, P., Tesche, M., Heinold, B., Kandler, K., Toledano, C. and co-authors. 2011. Dust mobilization and aerosol transport from West Africa to Cape Verde-a meteorological overview of SAMUM-2. Tellus 63B, this issue.

Lieke, K., Kandler, K., Scheuvens, D., Emmel, C., von Glahn, C. and co-authors. 2011. Particle chemical properties in the vertical column based on aircraft observations in the vicinity of the Cape Verde islands. Tellus 63B, this issue.

Linke, C., Möhler, O., Veres, A., Mohácsi, Á., Bozóki, Z. and co-authors. 2006. Optical properties and mineralogical composition of different Saharan mineral dust samples: a laboratory study. Atmos. Chem. Phys. 6, 3315-3323.

Miller, R. L., Tegen, I. and Perlwitz, J. 2004. Surface radiative forcing by soil dust aerosols and the hydrologic cycle. J. Geophys. Res. 109, $1-24$.

Moorthy, K. K., Babu, S. S., Satheesh, S. K., Srinivasan, J. and Dutt, C. B. S. 2007. Dust absorption over the "Great Indian Desert" inferred using ground-based and satellite remote sensing. J. Geophys. Res. 112, D09206.

Müller, D., Ansmann, A., Freudenthaler, V., Kandler, K., Toledano, C. and co-authors. 2010. Mineral dust observed with AERONET Sun photometer, Raman lidar, and in situ instruments during SAMUM 2006: Shape-dependent particle properties. J. Geophys. Res. 115, 11.

Müller, D., Mattis, I., Wandinger, U., Ansmann, A., Althausen, D. and co-authors. 2005. Raman lidar observations of aged Siberian and Canadian forest fire smoke in the free troposphere over Germany in 2003: Microphysical particle characterization. J. Geophys. Res. 110, D17201.

Myhre, G. and Stordal, F. 2001. Global sensitivity experiments of the radiative forcing due to mineral aerosols. J. Geophys. Res. 106, 18193-18204.

Persson, A. and Grazzini, F. 2007. User Guide to ECMWF forecast products v4.0, 153. 
Petzold, A., Rasp, K., Weinzierl, B., Esselborn, M., Hamburger, T. and co-authors. 2009. Saharan dust absorption and refractive index from aircraft-based observations during SAMUM 2006. Tellus 61B, 118-130.

Petzold, A., Veira, A., Mund, S., Esselborn, M., Kiemle, C. and coauthors. 2011. Mixing of mineral dust with urban pollution aerosol over Dakar (Senegal) - Impact on dust physico-chemical and radiative properties. Tellus 63B, this issue.

Petzold, A., Weinzierl, B., Huntrieser, H., Stohl, A., Real, E. and co-authors. 2007. Perturbation of the European free troposphere aerosol by North American forest fire plumes during the ICARTTITOP Experiment in summer 2004. Atmos. Chem. Phys. 7, 51055127.

Prospero, J. M., Ginoux, P., Torres, O., Nicholson, S. E. and Gill, T. E. 2002. Environmental characterization of global sources of atmospheric soil dust identified with the NIMBUS 7 Total Ozone Mapping Spectrometer (TOMS) absorbing aerosol product. Rev. Geophys. 40, 1002.

Schumann, U., Weinzierl, B., Reitebuch, O., Schlager, H., Minikin, A. and co-authors. 2011. Airborne observations of the Eyjafjalla volcano ash cloud over Europe during air space closure in April and May 2010. Atmos. Chem. Phys. 11, 2245-2279.

Sokolik, I. N., Winker, D. M., Bergametti, G., Gillette, D. A., Carmichael, G. and co-authors. 2001. Introduction to special section: Outstanding problems in quantifying the radiative impacts of mineral dust. J. Geophys. Res. 106, 18015-18028.

Tesche, M., Ansmann, A., Muller, D., Althausen, D., Engelmann, R. and co-authors. 2009. Vertically resolved separation of dust and smoke over Cape Verde using multiwavelength Raman and polarization lidars during Saharan Mineral Dust Experiment 2008. J. Geophys. Res. 114, 14.

Tesche, M., Ansmann, A., Müller, D., Althausen, D., Groß, S. and coauthors. 2011a. Optical and microphysical properties of smoke over Cape Verde inferred from multiwavelength polarization Raman lidar measurements. Tellus 63B, this issue.

Tesche, M., Groß, S., Ansmann, A., Müller, D., Althausen, D. and coauthors. 2011b. Profling of Saharan dust and biomass burning smoke with multiwavelength polarization Raman lidar at Cape Verde. Tellus 63B, this issue.

Virkkula, A. 2010. Correction of the Calibration of the 3-wavelength Particle Soot Absorption Photometer (3 PSAP). Aerosol Sci. Technol. 44, 706-712.

Virkkula, A., Ahlquist, N. C., Covert, D. S., Arnott, W. P., Sheridan, P. J. and co-authors. 2005. Modification, calibration and a field test of an instrument for measuring light absorption by particles. Aerosol Sci. Technol. 39, 68-83.

Weinzierl, B., Petzold, A., Esselborn, M., Wirth, M., Rasp, K. and coauthors. 2009. Airborne measurements of dust layer properties, particle size distribution and mixing state of Saharan dust during SAMUM 2006. Tellus 61B, 96-117.

Wendisch, M., Coe, H., Baumgardner, D., Brenguier, J. L., Dreiling, V. and co-authors. 2004. Aircraft particle inlets: state-of-the-art and future needs. Bull. Amer. Meteor. Soc. 85, 89-91.

Wernli, B. H. and Davies, H. C. 1997. A lagrangian-based analysis of extratropical cyclones. I: the method and some applications. Q. J. R. Meteorol. Soc. 123, 467-489.

Wernli, H. 1997. A Lagrangian-based analysis of extratropical cyclones. II. A detailed case-study. Q. J. R. Meteorol. Soc. 123, 1677-1706. 